NBER WORKING PAPER SERIES

\title{
ECONOMIC CONSEQUENCES OF HOSPITAL CLOSURES
}

\author{
Diane E. Alexander \\ Michael R. Richards \\ Working Paper 29110 \\ http://www.nber.org/papers/w29110 \\ NATIONAL BUREAU OF ECONOMIC RESEARCH \\ 1050 Massachusetts Avenue \\ Cambridge, MA 02138 \\ July 2021, Revised January 2023
}

We thank Caitlin Carroll, Atul Gupta, Ellie Prager, Molly Schnell, Ashley Swanson, and Bob Town for helpful feedback on an earlier version of this work. We are also grateful to the Federal Reserve Bank for providing valuable data resources. We also thank Aastha Rajan for her excellent research assistance. Any views expressed in this paper do not necessarily reflect those of the Federal Reserve Bank of Chicago or the Federal Reserve System. Any errors belong solely to the authors. The views expressed herein are those of the authors and do not necessarily reflect the views of the National Bureau of Economic Research.

NBER working papers are circulated for discussion and comment purposes. They have not been peer-reviewed or been subject to the review by the NBER Board of Directors that accompanies official NBER publications.

(C) 2021 by Diane E. Alexander and Michael R. Richards. All rights reserved. Short sections of text, not to exceed two paragraphs, may be quoted without explicit permission provided that full credit, including $\left({ }^{\circ}\right.$ notice, is given to the source. 
Economic Consequences of Hospital Closures

Diane E. Alexander and Michael R. Richards

NBER Working Paper No. 29110

July 2021, Revised January 2023

JEL No. H51,I11,I18,J21

\begin{abstract}
Hospitals anchor much of US health care and receive a third of all medical spending, including various subsidies. Nevertheless, some become insolvent and exit the market. Research has documented subsequent access problems; however, less is understood about broader implications. We examine over 100 rural hospital closures spanning 2005-2017 to quantify the effects on the local economy. We find sharp and persistent reductions in employment, but these localize to health care occupations and are more impactful in areas experiencing complete closures. Aggregate consumer financial health and housing markets appear unaffected by the shuttering of a rural hospital.
\end{abstract}

Diane E. Alexander

The Wharton School

University of Pennsylvania

Locust Walk

Philadelphia, PA 19104

and NBER

dealexa@wharton.upenn.edu

Michael R. Richards

Baylor University

Department of Economics

One Bear Place \#98003

Waco, TX 76798

michael_richards@baylor.edu

An online appendix is available at http://www.nber.org/data-appendix/w29110 


\section{Introduction}

A commonly observed economic phenomenon is the concentration of firms beyond what natural advantages would otherwise predict (Ellison and Glaeser 1999; Glaeser and Gottlieb 2009). The productivity benefits captured by firms from agglomeration can be many, including improved efficiencies in the acquisition of intermediate goods or services, thicker labor markets, greater concentration of human capital, and opportunities for knowledge spillovers (Moretti 2004; Glaeser and Gottlieb 2009; Greenstone, Hornbeck, and Moretti 2010). Moreover, the presence of a new business itself may be a catalyst for further job creation through increased demand for local goods and services (Moretti 2010). These economic possibilities and potential long-run benefits are familiar to government officials and are sometimes used as a rationale for direct policy intervention to preserve or promote greater business activity in a particular area-often through fiscal transfers and tax incentives (Clemens and Miran 2012; Wilson 2012; Bartik 2020). While the evidence for the effectiveness of such government involvement in local markets is mixed (Fox and Murray 2004; Ramey 2011; Slattery and Zidar 2020), this style of place-based policy has retained political appeal and is wielded in a variety of circumstances and markets across the US.

An industry where local and federal policymakers have frequently invoked (explicitly or implicitly) arguments related to agglomeration effects, jobs multipliers, and the health of local economies is US hospitals. Hospitals currently number more than 6,000 across the US and capture a third of annual health spending (i.e., over $\$ 1$ trillion per year). ${ }^{1}$ Hospitals also employ roughly 4.5 million workers nationally, a total which is not far behind those employed by full-service restaurants, and approximately a third of the size of the US manufacturing workforce (Fort, Pierce,

\footnotetext{
${ }^{1}$ Summary statistics regarding US national health expenditures are provided by the Centers for Medicare and Medicaid Services (CMS) here: https://www.cms.gov/research-statistics-data-and-systems/statistics-trends-andreports/nationalhealthexpenddata/downloads/highlights.pdf.
} 
and Schott 2018). Industry trade groups often go further and argue that US hospitals are directly or indirectly involved in as much as $\$ 3$ trillion of total economic activity per year (e.g., see AHA 2018), which portrays hospitals as economic anchors, if not engines for growth, within their surrounding communities. ${ }^{2}$

Yet, hospitals' duality as a care supplier and key employer does not insulate them against financial struggles. These challenges are often most severely felt within rural communities, where low occupancy rates coupled with high fixed costs can generate negative and unsustainable margins for hospitals (Wishner et al. 2016; Frakt 2019; Bai et al. 2020; GAO 2020; Kacick 2020). A growing wave of insolvencies and subsequent closures has recently taken place-leading some to declare a crisis for rural America that may worsen over time (Chartis Center for Rural Health 2020; Kacick 2020). While the evidence on the effects of hospital closures on health outcomes is mixed and debated (e.g., Rosenbach and Dayhoff 1995; Joynt et al. 2015), studies have found that hospital closures impede patients' access to care, especially for time-sensitive conditions in more rural geographies (Buchmueller 2006; Carrol 2019; Gurjal and Basu 2019; Song and Saghafian 2019; GAO 2020; Miller et al. 2020; McCarthy et al. 2021; Nikpay et al. 2021). This wave of closures is also occurring against a backdrop of more pronounced provider shortages, greater disease burden, and lower life expectancy among rural areas when compared to their urban counterparts (Iglehart 2018; Cross et al. 2020; Cross, Califf, and Warraich 2021). ${ }^{3}$

\footnotetext{
${ }^{2}$ Such arguments and/or views have been persuasive outside of those with vested interests in the hospitals industry as well. As an example, the Federal Reserve Bank of Philadelphia includes hospitals as a key component of its recently launched Anchor Economy Initiative. Details can be found here: https://www.philadelphiafed.org/community-development/workforce-and-economic-development/anchor-economyinitiative.

${ }^{3}$ Some research suggests that recent Medicaid expansions have benefited rural hospitals' finances to some degree, and perhaps forestalled some closure events (Lindrooth et al. 2018; Bai et al. 2020).
} 
Furthermore, the loss of a rural hospital could reflect a market failure if agglomeration economies exist and cause other rural health care-related industries' productivity and/or business viability to be negatively impacted through the subsequent loss of local workers, talent, and/or access to medical technology following closure. Likewise, the closure of a rural hospital could deliver a broad negative demand shock for other local goods and services (inside and outside of health care), especially in the non-tradeable sector.

In this paper, we aim to better understand the broader economic ramifications of these hospital closures. We do so by combining a census of rural hospital closures across the US from 2005 through 2017 (roughly 120 closures in total) with a unique collection of granular countylevel measures on employment, consumer financial status, and housing market activity. ${ }^{4} \mathrm{We}$ leverage a county-level differences-in-differences empirical framework to estimate if, and to what degree, hospital exits in rural areas impact the local economy. We use multiple estimation strategies to address potential issues with the differential timing in treatment-i.e., closure events — over our analytic period (e.g., see Callaway and Sant'Anna 2021; Goodman-Bacon 2021) and to ensure the robustness of our findings across estimation approaches.

Our estimates reveal strong and sharp negative effects of rural hospital closures on local employment levels, with declines that are confined to health care jobs. The magnitude of the effect, however, implies that the job losses extend to health care workers outside of direct hospital employment, which is consistent with co-location benefits between hospitals and other local medical industries (i.e., a within-sector agglomeration effect from the presence of a local hospital). Yet, there are no clear effects of hospital closure on aggregate consumer credit worthiness or

\footnotetext{
${ }^{4}$ Regarding housing markets, other research demonstrates the potential for "desirability effects" to influence housing values (e.g., Currie et al. 2015). In our context, the lack of a local hospital could plausibly depress demand for moving to and/or remaining in the residential area even for those with no employment ties to the health care sector.
} 
financial health in these communities. We also find no evidence consistent with a worsening housing market after a rural hospital closure - at least not over the short- to medium-run.

One potential drawback of our primary empirical strategy is that it could miss some of the effects of hospital closures on the local economy if substantial spillovers exist across county borders. Such spillovers could occur either because people live in one county and work in another or because the closure event spurs them to leave the county and relocate nearby. Thus, we investigate the existence of spillover effects of hospital closures onto the labor markets of adjacent counties. The results do not indicate that health care workers relocate from the county experiencing a rural hospital closure) to a neighboring county — suggesting that any worker migration induced by the closure is more diffuse.

We also examine heterogeneity in effects according to characteristics of the closure as well as the baseline local labor market dependence on health care industries. We do find differential effects depending on whether any of the hospitals' assets were repurposed, as opposed to a complete shutdown of health care delivery. Specifically, full closures are associated with stronger economic effects compared to partial closures for health care employment - though the negative impact is still present and substantive for partial closures, and neither closure type affects nonhealth care employment levels. We find no evidence consistent with differential labor market effects of the closure of rural Critical Access Hospitals (CAHs) compared to other closures, or hospitals in counties where the health care sector was a larger share of local jobs when compared to counties with less of a reliance on the health care industry pre-closure. The variation used in these heterogeneity analyses is potentially endogenous and consequently requires more circumspect interpretation than our main results. However, the analyses still offer some useful 
nuance that can be informative for policymakers that may be trying to minimize the economic fallout from rural hospital closures.

While a modest number of studies on the economic effects of hospital closures in rural communities exist, the conclusions have been indeterminate-perhaps due to differences in estimation strategies, underlying data, and/or the fact that much of the literature does not account for the potential of reverse causality. ${ }^{5}$ A contemporary study from Edmiston (2019) finds closures between 2011 and 2016 to be negatively associated with general employment and wages; yet, the analyses are primarily descriptive, rather than causal, in nature. A recent working paper from Vogler (2021) reports sweeping negative effects of rural hospital closures, primarily focusing on overall labor market outcomes. ${ }^{6}$ We also find significant effects of closures on employment; however, our industry-level results take this analysis a step farther and show that these effects are limited to the health care sector, with no evidence of spillovers. Our data on consumer finances and housing markets additionally allow for a more detailed examination of closures' impacts on local economic activity.

In sum, our empirical strategies and broad set of local economic data offer a comprehensive collection of relevant findings that fill an important gap in the literature. An incomplete

\footnotetext{
${ }^{5}$ Earlier work, for example, estimated lower consumer welfare when a rural community loses a hospital (McNamara 1999), and Holmes et al. 2006 finds lower per capita income and higher unemployment when a sole community hospital closes - but the estimation approach does not reveal whether the outcomes were evolving similarly in the lead up to a closure. Conversely, looking at a shorter time frame (1998-2000) in three states, Ona, Hudoyo, and Freshwater (2007) fail to detect any economic effects from rural hospital closures, which aligns with equivocal or null results from studies focused on communities in the 1980s (Probst et al. 1999; Pearson and Tajalli 2003).

${ }^{6}$ Additionally, it is difficult to directly compare our results to those of Vogler (2021), as much of the data, data construction, and estimation approaches for closure effects strongly differ across the two papers. The one dataset in common between our analyses and Vogler (2021) is the Quarterly Census of Employment and Wages (QCEW); we both find a decrease in log employment after hospital closures - though Vogler reports non-health care jobs as being a key driver of the employment declines. Our estimation strategies and subsequent results are not consistent with such an interpretation.
} 
understanding of the implications from rural hospital closures matters since significant public resources have subsidized these hospitals for roughly four decades, despite a lack of consensus around the full costs - both health and economic - to communities that experience a hospital closure. The bulk of these funds come from the federal Medicare program and add more than $\$ 4$ billion to the public insurer's annual expenditures (MedPAC 2016). Our estimates reveal that the direct and indirect effects of rural hospital closures are ultimately sector-specific. Demonstrating that the negative impact from these closures is restricted to health care employment, however, does not necessarily imply that sustaining financially struggling rural hospitals via subsidies is unjustified. Adjustment costs for affected workers can be large and unevenly felt following a negative economic shock (e.g., see Artuç, Chaudhuri, and McLaren 2010; Autor et al. 2014; Balsvik, Jensen, and Salvanes 2015; Utar 2018; Traiberman 2019). However, as we discuss in Section 7, there are reasons to believe that contemporary health care workers exposed to a hospital closure may experience smaller labor adjustment frictions when compared to workers in other industries following the loss of a large employer (e.g., a manufacturing plant).

While the US health care sector is a known source of jobs and employment growth (Baicker and Chandra 2012; Frogner 2018; Stiegler, Martiniano, and Forte 2021), a substantial portion of the sector's financing comes through taxation. Important tradeoffs must therefore be considered when using public financing to promote the sector's role in employment to avoid fomenting a “wildly inefficient jobs program" (Baicker and Chandra 2012). If rural economies, in particular, are sufficiently resilient to withstand the loss of a local inpatient hospital, especially when some of the health care industry remains, federal funds might witness greater returns when targeting other economic challenges facing these communities, rather than being used to forestall an inpatient facility's market exit. 


\section{Background: Rural Hospital Closures and Policy Considerations}

Hospitals provide a variety of medical services - some of which have limited or no substitute (i.e., non-hospital) suppliers - and are also known to perform a variety of indirect and socially valuable functions, such as implicitly financing care for the uninsured (Garthwaite, Gross, and Notowidigdo 2018) and even supplying social services in some circumstances (Ross Johnson 2018). Yet, they are costly to develop and operate, especially within more economically challenging environments. These industry features have led to a variety of policy interventions that focus on attracting and sustaining hospitals in more rural locations.

When addressing the potential closure of rural hospitals, policymakers are primarily motivated by two salient rationales: preserving access and preserving jobs in these communities (Associated Press 2020b). While issues related to health care access are typically of immediate concern, a wider range of potential negative economic consequences are also often highlighted. ${ }^{7}$ Local media reports and isolated case studies of finalized or looming rural hospital closures often remark on the number of individuals previously working for the hospital, as well as community leader concerns over retaining as well as attracting other businesses to the area (Wishner et al. 2016; Associated Press 2019, 2020a). It is at least plausible that the compounding loss of high earners, as well as central figures in the local health care economy, could further challenge these

\footnotetext{
${ }^{7}$ Research focused on the 1980s argues that rural towns suffer losses of local physicians when a key hospital shuts down (Hart, Pirani, and Rosenblatt 1995). More recently, Drew Germack, Kandrack, and Martsolf (2019) examined physician supply following rural hospital closures and found suggestive evidence of negative economic effects when using American Hospital Association and the Area Health Resource Files databases. Of note, the event study analyses in Germack, Kandrack, and Martsolf (2019) demonstrate substantive differential trending in the years leading up to an observed closure in the AHA data, and statistically significant post-closure effects are not evident until 4-6 years after the county experienced a closure.
} 
communities and their local businesses (health care and non-health care) in the wake of losing their local hospital.

In response to a series of rural hospital closures in recent years, legislation is currently being introduced at both the federal and state levels to stem further losses. More specifically, the Coronavirus Aid, Relief, and Economic Security (CARES) Act included special transfers restricted to roughly 1,800 rural hospitals across the US (Brady 2020). The bipartisan Save Rural Hospitals Act - introduced in the US House of Representatives in 2017—would undo spending cuts for these hospitals and possibly increase some of their payments (Sharfstein 2016; Wishner et al. 2016). ${ }^{8}$

Yet, it remains an open question as to whether subsidies for rural hospitals are appropriately targeted or the most efficient use of public funds. The Critical Access Hospital (CAH) designation, which was developed with the aim of propping up financially ailing rural hospitals, provides a good example of the difficulties involved. ${ }^{9}$ Receiving the $\mathrm{CAH}$ designation requires accepting certain constraints (e.g., maintaining inpatient bed capacity, but fewer than 25 beds, and limiting their average patient length of stay) but also entitles a hospital to generous cost-based reimbursements from Medicare (as opposed to the standard prospective payment system used to reimburse other hospitals). Roughly half of all current rural hospitals across the US are part of the CAH program (MedPAC 2016; Iglehart 2018; Bai et al. 2020). Some recent research finds that the $\mathrm{CAH}$ program mitigates the risk of rural hospital closure - though the net effects on consumer welfare are not necessarily favorable (MedPAC 2012; Gowrisankaran et al. 2018; Carrol 2019). However, $16 \%$ of CAHs are within fifteen miles of another hospital (MedPAC 2012) —indicative

\footnotetext{
${ }^{8}$ The Save Rural Hospitals Act was introduced in the house in 2017, sponsored by Representatives Sam Graves (RMO) and Dave Loebsack (D-IA).

${ }^{9}$ At this time, just under 2,000 hospitals across the US are considered rural community hospitals (around $35 \%$ of all community hospitals). Information provided by the American Hospital Association (AHA) and found here: https://www.aha.org/statistics/fast-facts-us-hospitals.
} 
of readily available substitute facilities and access points for rural consumers at only modest additional travel costs. Furthermore, among CAHs that closed in 2014, their median Medicare payment rate was $\$ 500,000$ above what these same hospitals would have received under the standard Inpatient Prospective Payment System (IPPS) that has applied to most hospitals in the US since 1983 (MedPAC 2016). In other words, Medicare spent millions of dollars in excess payments for hospitals that still failed to remain solvent under a generous (i.e., cost-based) reimbursement system and that may have had sufficient substitutes available to local patients.

A growing policy chorus has emerged to encourage more tailored interventions that explicitly reflect rural medical service needs and can ensure their long-run availability for rural residents (MedPAC 2016). For example, a recent federal policy initiative aims to create a new hospital classification, "Rural Emergency Hospital", for Medicare reimbursement that would allow a facility to narrow its scope to emergency care and outpatient services only (i.e., no longer maintain inpatient beds) and then receive special payments and other subsidies for these services (Kacick 2020; Cass 2022; Kacick 2022). Proponents argue that such customization can maintain sufficient rural care access while lowering some of the cost burden on public finances. In what follows, our empirics directly speak to these arguments, by taking a comprehensive look at the economic fallout from rural hospital closures and if it varies by closure conditions.

\section{Data}

\subsection{Rural Hospital Closures}

The Cecil G. Sheps Center for Health Services Research at the University of North Carolina leverages a variety of sources to track rural hospital closures across the US dating back to 2005. A rural hospital is defined as a non-federal, short-term, general acute care hospital that operates 
outside of a metropolitan county, operates within a census rural-urban commuting area (RUCA) type 4 county, or operates as a designated $\mathrm{CAH}$. The center follows the federal Office of Inspector General in defining a closed hospital as "... a facility that stopped providing general, short-term, acute inpatient care." Hospital mergers, changes of ownership, or CAH conversions not considered closures. Additionally, if a hospital closed and then reopened within the same calendar year and physical location, it is not recorded as a rural hospital closure in the database. The data also differentiate between full hospital closures and partial closures, whereby the inpatient unit is discontinued but other services (e.g., emergency care, rehabilitation services, or outpatient care) remain. Importantly, each closure (full or partial) event has a precise calendar date and associated county location. These features make our subsequent empirical strategies feasible, and these data are also publicly available. ${ }^{10}$

Figure 1 displays the corresponding trends in national closure counts by the type of closure. Rural hospital closures have accelerated since the Great Recession, and within a typical year, the majority of closures are full market exits. Figure 2 characterizes the geographic dispersion of these closures over the 2005-2019 period. Rural hospitals have ceased operations within most regions of the US; though, certain states (e.g., Texas) have witnessed comparatively larger waves of closures during this time.

\subsection{Employment}

\footnotetext{
10 The data and their full description can be accessed here: https://www.shepscenter.unc.edu/programsprojects/rural-health/rural-hospital-closures/. Of note, for a minority of closure cases, we had to supplement the Center's information with our own web-based information gathering to determine the exact closure taxonomy (i.e., full or partial) for a given closure event. A few closure events could not be cleanly assigned to a closure type.
} 
Our county-level employment information comes from the Quarterly Census of Employment and Wages (QCEW), which is collected and made available by the US Bureau of Labor Statistics. The data provide counts of employment by industry, and are estimated to cover more than $95 \%$ of all US jobs. We use the quarterly data from 2001 through 2018, and more specifically, the counts of total employment, private sector employment, health and education private sector employment, and non-health and non-education private sector employment. The latter three counts are defined by the accompanying private sector NAICS codes. We restrict our analysis to counties with complete (i.e., non-missing) count information for each employment sector for each of the 72 quarters belonging to our 2001-2018 QCEW data.

One drawback of these data is the inability to separate education employment from health services employment within the combined NAICS code (code 1025). However, the clear linkage between our market events of interest (i.e., hospital closures) and health care industries suggest that within-county changes in employment levels proximate to these market events should be overwhelmingly driven by adjustments to the local health care workforce, as opposed to education jobs. Furthermore, many of these communities' education industry workers are likely to work in the public sector, rather than the private sector. Thus, we believe immediate changes in employment in the quarter-years following a rural hospital closure within the combined education and health care services NAICS code can be plausibly attributed to those working in health care. For brevity, we refer to the category of combined health and education private sector employment as health care employment throughout the paper.

\subsection{Consumer Financial Health}

Our data on consumer financial information comes from the Federal Reserve Bank of New York Equifax Consumer Credit Panel (FRBNY CCP/ Equifax). This dataset consists of detailed credit- 
report data for a unique longitudinal panel of individuals and households in quarterly increments from the first quarter of 2000 to the first quarter of 2020. The anonymized panel tracks a nationally representative 5\% random sample of individuals in the US with a credit file and a social security number. The underlying data are at the individual level, which we aggregate to the county-quarter level. ${ }^{11}$ From the FRBNY CCP/Equifax we construct several summary measures of consumer financial health. In particular, we construct the average Equifax Risk Score (referred to as 'risk score' from here on), the average number of bankruptcies in the last 24 months, the average total balance past due, and the average number of $3^{\text {rd }}$ party collections (i.e., collections not handled by the original creditor) in the past twelve months. ${ }^{12}$

\subsection{Housing Market Activity}

The Home Mortgage Disclosure Act (HMDA) Database is composed of records from originations and purchases of mortgages, as well as from loan applications that were withdrawn or denied. Included in the data are loan characteristics and outcomes, collateral characteristics, and information on applicant demographics. The data is reported by depository institutions and certain for-profit, non-depository institutions, as required by the original Home Mortgage Disclosure Act legislation from 1975, as well as later amendments. ${ }^{13}$ The Federal Financial Institutions Examination Council (FFIEC) compiles the data, which is available annually; the collection effort

\footnotetext{
${ }^{11}$ We drop any county-quarter observations with less than 20 underlying observations for privacy concerns.

${ }^{12}$ FRBNY CCP/Equifax data assets are only the source of the analytic data containing these specific outcomes describing consumer financial health; all of the calculations or subsequent findings and interpretations relying on this data source are conclusions of the authors; any mistakes are our own.

${ }^{13}$ Not all lenders must participate in HMDA reporting. The requirements, which have changed over time, depend on the lender's asset size, whether it participates in residential mortgage lending, and whether it has a home or branch office in a metropolitan statistical area, among other factors.
} 
has been spearheaded by the Consumer Financial Protection Bureau (CFPB) since the 2017 reporting year. In order to look at county-level housing market activity in the years before and after the hospital closure, we look at the total number of loans originated, denied, and purchased in each county-year from 2001 to 2018 . We also construct a measure of the average loan amount in thousands of dollars for these loan categories, and separate loans into three loan purpose categories (home purchase, home improvement, refinance), and by applicant race categories (white, black, and other) in order to see whether there is any change in the composition of loans over the time period.

We note that there are 243 counties not included in our QCEW analytic data that are included in the Consumer Credit Panel and HMDA analytic data. These counties, which are primarily in the control group, have on average lower population and correspondingly lower loan volume than those which are included in the QCEW data. However, they look similar to the other control counties in terms of loan size and consumer financial health. Our results are ultimately insensitive to the exclusion of this subset of smaller counties from analyses using the Consumer Credit Panel and HMDA data sets.

\section{Empirical Strategy}

To examine the effect of rural hospital closures on the local economy, we use several alternative differences-in-differences (DID) estimation strategies. Conceptually, for each estimation method used, we are comparing counties that experience a closure to those that did not, before and after the closure event. Our treated counties are consequently those that experience a rural hospital closure over the $2005-2017$ period. We remove counties (32 in total) with a rural hospital closure in 2018 or 2019 due to insufficient post-period data and concerns that their pre-closure experiences 
could distort the behavior of the control group, leading to bias in our DID estimates. ${ }^{14}$ We then use counties that never experience a closure during this time interval, have at least $25 \%$ of the county population classified as rural according to the 2000 Census, and have a hospital present in the county as of 2005, to comprise the control comparison group. The latter control group inclusion characteristic is derived from the American Hospital Association (AHA) annual survey from 2005, and restricts to non-government, general acute care hospitals. While the exact number of counties in the analysis varies slightly by dataset, roughly 120 counties are classified as treated, and more than 1,600 counties as controls (see Table 1).

Table 1 summarizes our outcome variables across the treatment and control county groups. The overall population, and hence size of the labor market and housing market activity, is larger, on average, among counties that experience a rural hospital closure during the analytic period when compared to the control group counties. However, the dollar ('000) amounts of the housing loans as well as income profiles of borrower applicants is quite similar across the treatment and control groups in Table 1. Similarly, average credit risk scores and bankruptcy rates over the preceding 24 months are for counties losing their hospitals are on par with those from counties that do not experience this market event during the study period.

Our primary empirical challenge stems from the differential timing in closure among our treatment group counties. While our control group is overwhelmingly comprised of never treated units, there could still be concerns that the standard generalized difference-in-difference (DID) estimation (i.e., two-way fixed effects estimation) could lead to contaminated comparisons

\footnotetext{
14 There is one case of a county with multiple rural hospital closures during our time period: Gibson County, TN, which had two partial closures in the same quarter (2014Q1). We do not make any adjustments based on this case of two closures in the same quarter, effectively treating it as a single closure event. All results are unchanged if we drop Gibson County from our analysis; results available upon request.
} 
stemming from the staggered timing of treatment. Additionally, this style of analysis has been shown to be sensitive to the underlying weighting, which could distort our resulting estimates and/or the pre-closure evolution of our outcomes of interest. We therefore estimate and present the results from three distinct DID specifications (described below) in order to be transparent with our empirical results and to ascertain that any inferences drawn are consistently supported across estimation strategies and therefore not method dependent. Accordingly, we do not prioritize or prefer any one of the three DID methods; however, in the interest of space, we present subsets of findings in the appendices where appropriate.

\subsection{CSDID}

Our first DID method is that developed by Callaway and Sant'Anna (2021) - referred to as 'CSDID' in what follows. In contrast to two-way fixed effects (TWFE) estimation methods, CSDID is designed to sensibly aggregate heterogeneous treatment effects in settings with staggered treatment timing. Intuitively, the CSDID estimator infers the counterfactual outcomes for treated units using trends in outcomes for an appropriately chosen "clean" control group of untreated units (Roth et. al 2022). The group-time average treatment effect on the treated is the building block of the estimator, where group refers to a cohort of observations which are all treated with a hospital closure at the same time. This group-time average treatment effect on the treated is identified by comparing the expected change in an outcome for a cohort $g$, between periods $(t-1)$ and $t$ to that for a control group that is not-yet treated at period $t$. A weighted average is then taken across the different closure cohorts to construct a (weighted) average of the treatment effect in each time period before and after closure. This approach has two key advantages over standard 
TWFE regressions, as it both allows for arbitrary heterogeneity of treatment effects, and makes transparent which units are being used as a control group. ${ }^{15}$

Our resulting estimates from the CSDID application capture any differential behavior changes for the counties experiencing a rural hospital closure during the 12 quarters before and through the 12 quarters after the rural closure event $(t=0)$. Throughout the paper we present our results primarily in event study figures, as it allows the reader to visually confirm the absence of differential pre-trends between the treated and control groups since (generalizations of) the parallel trends assumption are needed to support a causal interpretation of the research design across all three DID specifications. Furthermore, given the potential for reverse causality when looking at the effect of hospital closures on the local economy, the behavior of the outcomes in the years before a hospital formally closes can also be of independent empirical interest. ${ }^{16}$

Our outcomes are levels of employment for a given worker type for a given county-quarteryear in the QCEW data (and log transformed), and our aggregate consumer financial health and housing market outcomes are as described in Section 2.3 and Section 2.4. In each estimation approach, we adapt the analytic setup when studying the housing market outcomes, as those data are annual, rather than quarterly. Specifically, we condense the event-time range to $[-3,+3]$ annual time periods relative to the hospital closure event. The application of the CSDID event study model is otherwise unchanged from its use on the quarterly analytic data sets for employment and consumer finances outcomes, which is also the case for our subsequent two alternative DID estimation methods.

\footnotetext{
${ }^{15}$ For further details, as well as discussion of the benefits and drawbacks of this and other recently developed approaches to remedy the problems of TWFE analyses in settings with staggered treatment timing, see Roth et. al (2022).

${ }^{16}$ For example, previous work demonstrates that rural hospitals financial performance suffers during the lead up to the actual closure event, especially within a year of closure (Kaufman et al. 2016; Bai et al. 2020; Chartis Center for Rural Health 2020).
} 


\subsection{Stacked DID}

Our second DID estimation approach relies on a "stacked" event study methodology (referred to as 'Stacked DID' in what follows). At a high-level, the method aligns the unit-specific time series (i.e., each of our counties belonging to the analytic sample) so that all units contribute an identical number of pre- and post-period observations, and thus both prevents the estimation from over(under) weighting any particular treatment unit, as well as and preventing "early treated" units from being compared to "late treated" units.

To implement the estimation, we first only include treated counties where we can observe their outcomes 12 quarters before the hospital closure event and 12 quarters after (i.e., those exhibiting full information pre- and post-closure). We then take all available control group counties and randomly assign them a placebo closure date based on the sample of actual closure dates observed within our treated units. Anchored to a control unit's placebo date, we retain the 12 quarters before and after the randomly assigned placebo date. All potential control units without the full $[-12,+12]$ data available are subsequently excluded from the Stacked DID regressionsparalleling what is done for the treatment group. This process leaves us with a balanced panel (25 quarters in total) of treatment and control counties where the $t=0$ time point is either the actual hospital closure quarter (treated units) or a placebo closure quarter (control units) so that all units contribute the exact same amount of analytic information. ${ }^{17}$ We then estimate the corresponding event study specification:

\footnotetext{
${ }^{17}$ In other words, we have deliberately imposed an analytic environment where treatment "turns on" at the same time for all treated units and there is no up- or down-weighting of treated units based on their specific timing of treatment during our full study period.
} 


$$
Y_{c t}=\sum_{\substack{j=-12 \\ j \neq-4}}^{12} \gamma_{j}\left[\mathbf{1}\left(T_{c}+j\right)\right]+\sum_{\substack{j=-12 \\ j \neq-4}}^{12} \delta_{j}\left[\mathbf{1}\left(T_{c}+j\right) * \mathbf{1}\left(\text { Closure }_{c}\right)\right]+\lambda_{c}+\tau_{t}+\varepsilon_{c t}
$$

Equation (1) includes county $(\lambda)$ and quarter-year $(\tau)$ fixed effects. Our outcomes $(Y)$ are as described above. The variable $T_{c}$ represents the quarter-year a given treated county $(c)$ experiences a rural hospital closure and the anchor placebo date for our control group counties. We then create a series of quarterly event-time dummies $(j)$ that capture the periods leading up to and following the closure event and span three years in each direction. The indicator $\mathbf{1}\left(\right.$ Closure $\left._{c}\right)$ is an indicator for counties which actually experienced a hospital closure during our sample period. The omitted time point is one year (i.e., $t-4)$ prior to the county's true closure or placebo closure event at time $T_{c}$.

The set of parameters $\left(\gamma_{j}\right)$ inform how the control counties are trending around the placebo closure event, whereas the series of $\left(\delta_{j}\right)$ parameters show the differences in event time between the closure counties and control counties. And across all three analytic data sets and accompanying estimations, the standard errors are clustered at the county level throughout. ${ }^{18}$

\subsection{TWFE DID}

\footnotetext{
${ }^{18}$ We have also implemented Equation (1) when excluding quarter-year fixed effects (i.e., effectively ignoring the actual calendar time belonging to a given analytic unit's $[-12,+12]$ truncated time series. The results from the Stacked DID are virtually identical. Also, we intentionally avoid time-varying county characteristics as right-handside variables. Given that we are examining the economic impacts of rural hospital closures changes in any commonly used geographic characteristics (e.g., population demographics, poverty rates, etc.) are potential outcomes from the market shock. Thus, their inclusion in the estimation would risk endogeneity bias from using potential outcomes as covariates (i.e., using "bad controls").
} 
Our final estimation method is the longstanding 'TWFE DID' specification, which is also the empirical approach used in other recent economics research studies examining health care market events (e.g., Eliason et al. 2019; Prager and Schmitt 2021). In our empirical context, the large number of never-treated control counties relative to counties experiencing a closure is analytically helpful when using TWFE estimation to recover a DID estimate since the overwhelming majority of our counties are "never treated" units, meaning that our key $2 \times 2$ comparison is almost entirely between treated units and never treated units, which avoids complications from a large number of "always treated" units and/or when most of the units are eventually treated in the presence of treatment effect heterogeneity (see Goodman-Bacon (2021) for a detailed discussion of the generalized differences-in-differences econometric properties). However, as previously noted, other estimation and inference complications may still arise, which underscores the value of presenting the TWFE version side-by-side with the CSDID and Stacked DID approaches previously described.

The implementation of the TWFE is straightforward:

$$
Y_{c t}=\sum_{\substack{j=-12 \\ j \neq-4}}^{-1} \beta_{j}\left[\mathbf{1}\left(T_{c}+j\right)\right]+\sum_{j=0}^{12} \theta_{j}\left[\mathbf{1}\left(T_{c}+j\right)\right]+\lambda_{c}+\tau_{t}+\varepsilon_{c t}
$$

Equation (2) includes county $(\lambda)$ and quarter-year $(\tau)$ fixed effects. The variable $T_{c}$ represents the quarter-year a given treated county $(c)$ experiences a rural hospital closure. We then create a series of quarterly event-time dummies $(j)$ that capture the periods leading up to and following the closure event and span three years in each direction. The omitted time point is four quarters (i.e., one year) 
prior to the county's closure event at time $T_{c}$. The set of pre-closure parameters $\left(\beta_{j}\right)$ inform how the treatment and control counties are trending prior to the treatment group's rural hospital closure events, and the series of post-closure $\left(\theta_{j}\right)$ parameters flexibly capture any differential changes in our treatment group counties following the closure events. Standard errors are again clustered at the county level throughout.

\subsection{Control Group Sensitivity}

Beyond exploring alternative estimation approaches, we also thoroughly test the robustness of our main specifications to using different criteria for defining control group counties. Specifically, we adjust the chosen threshold of rurality for analytic sample inclusion from $25 \%$ to $50 \%$ and then to $75 \%$ of the county's population based on the 2000 US census information. Similar estimates across control group options from this exercise, coupled with our event study results across multiple DID methodologies, offer assurances that our empirical inferences are robust and valid.

\section{Effects on Employment, Consumer Financial Health, and Housing Markets}

\subsection{Employment}

We begin by examining the most proximate outcome to a rural hospital closure: changes in employment. In Figure 3, we display the event study results for each of the three estimation methods, and for each method, we separately capture logged changes in private sector health care industry and non-health care industry private sector employment. It is clear from panels (A), (C), and (E) in that health care jobs are sharply and negatively affected by rural hospital closures. Across all three estimation approaches, there is no differential pre-trend between treatment and control counties in health care employment during the three-year lead up to the rural hospital 
closure, but following closure, 10-12\% fewer workers are employed in health care jobs - a decline that is both swift and persistent over the next three years. ${ }^{19}$

While health care jobs are strongly affected, we find no such pattern for non-health care private sector employment in panels (B), (D), and (F). Irrespective of the estimation approach used, non-health care private sector jobs are stable both in the lead up to the rural hospital closure and after the closure has taken place. The event time point estimates remain near zero throughout the estimation window and are precisely estimated. Depending on the specification, we can reject a negative effect of closures on non-health care private sector employment larger than 2-3\% (i.e., approximately a fifth of the size of the effect of closures on health care employment observed in the three lefthand-side panels of Figure 3). Thus, there is no evidence of a negative local spillover effect to employment in other industries, nor job switching out of health care and into other sectors of the economy for these rural labor markets - at least within three years post-closure.

Figure 4 re-examines the rural hospital closure effects at more aggregate employment level outcomes to better gauge the importance of the health care industries job losses demonstrated in Figure $3 .{ }^{20}$ Panels (A) and (B) in Figure 4 show that the pronounced negative effects on health care employment are detectable even in the broader employment measures when using the CSDID method. Private sector jobs, in particular, shrink by approximately $2 \%$ after a rural hospital closure and do not recover over the subsequent three years (Figure 4(B)). Thus, health care workers are a sufficiently large part of the local labor force that their losses generate appreciable declines in overall employment levels - despite the jobs decline from a rural hospital closure localizing to

\footnotetext{
${ }^{19}$ Percent changes are calculated by exponentiating the coefficients since the employment outcomes are in logs.

${ }^{20}$ Panels (C) and (D) are repeated from the CSDID estimation presented in Figure 3 for ease of comparison with the employment outcomes at higher levels of aggregation.
} 
health care-related industries. Appendix Figures A1 and B1 provide the results for the Stacked and TWFE DID estimations, respectively; the patterns in these figures closely follow those produced with the CSDID method in Figure 4. Likewise, altering the inclusion criteria for control group counties (Appendix Figure D1) has no material effect on the estimates and inferences across our employment outcomes.

As the average rural hospital that closes in our data has 187 full- and part-time employees on its payroll prior to closure, the $10 \%$ reduction in aggregate health care jobs observed, on average, in Figures 3 and 4 (relative to a treatment group average of 3,868 workers, see Table 1) implies that approximately half of the lost jobs are directly tied to the closing hospital itself. ${ }^{21}$ To the extent that not all the health care jobs lost are provided by the closing hospital, the estimates are consistent with health care-specific agglomeration economies existing in these rural counties, which lead to negative (within-sector) externalities when the local hospital shuts down. There are many examples of hospital-sensitive (but not hospital-provided) jobs, such as specialty physicians (e.g., surgeons) that rely on hospital facilities and technology, medical suppliers that stock hospital inventories and/or provide durable medical equipment to physicians and patients, and/or post-acute care firms (e.g., home health agencies) that often depend on local hospitals for patient referrals. Additionally, the loss or downsizing of any of these indirectly affected health care firms can lead to further auxiliary job losses for affiliated clinical staff, suppliers, and/or administrative support staff belonging to these firms.

\footnotetext{
${ }^{21}$ To calculate the number of employees at the closing hospitals, we leverage the American Hospital Association (AHA) annual hospital survey data by matching (via hospital name and exact address) our rural closure hospitals to corresponding information in the AHA data. Not all of our closing hospitals can be found in the (voluntary) AHA data; however, we are able to match 96 closure hospitals that have their final participation in the AHA survey within two years of their actual closure date. Using the average number of health care workers from the treatment group's pre-closure data years $(3,852)$ generates a very similar back-of-the-envelope estimate of approximately half of jobs lost are outside the hospital.
} 


\subsection{Consumer Financial Health}

While we find clear evidence of a causal impact of rural hospital closures on local employment in health care industries, we find no evidence of negative consequences on average consumer financial health in these same areas. The CSDID event study results in Figure 5 show stable aggregate credit risk scores, debt amounts past due, and number of bills in collection past 12months both before and after the rural hospital closure. Figure 5 (B) perhaps suggests a small increase in the county-level bankruptcy rate around six months after the hospital exits the market; however, this pattern is both imprecisely estimated and does not hold up in the other two estimation strategies (Appendix Figures A2 and B2). ${ }^{22}$ Likewise, while the Stacked and TWFE estimation strategies suggest a small negative effect on credit risk scores (Appendix Figures A2 and B2, respectively), this effect is not robust to the CSDID estimation strategy. Across all measures of consumer financial health, we can reject deteriorations in these measures larger than $10 \%$ relative to the mean in closure counties; for risk scores we can further reject decreases larger than $0.2 \%$, relative to the mean in closure counties (Table 1).

\subsection{Housing Markets}

Similarly, there is no evidence that the demand for housing or willingness to lend to prospective housing buyers is affected by the loss of the local rural hospital. Figure 6 presents the CSDID event study results for the annual number of loans originations, denials, and purchases on the secondary market. We continue to focus on a three-year window around the closure event, though these

\footnotetext{
${ }^{22}$ The small increase in bankruptcies following hospital closures in Figure 5 (B) is also not statistically significant in a more parsimonious specification, which parallels the estimation strategy of Figure 5 but does not estimate separate event time coefficients-i.e., it DID averages over the full post-period (see Table E1).
} 
outcomes are now at the county-year level. As in Figure 5, the event time estimates in Figure 6 show that the number of loans originated (Figure 6A), denied (Figure 6B), and purchased (Figure 6C) are stable during the three-year window before and after a rural hospital closure. While the estimates are somewhat imprecise, again neither of the other two empirical strategies (Appendix Figure A3 for the Stacked estimation and Appendix Figure B3 for the TWFE estimation), nor a more parsimonious specification (Table E1) reveal a statistically significant effect of rural hospital closures on local housing markets. Null findings are also present when we stratify loans by purpose (home purchase, refinancing, or home improvement) in Appendix Figure D2 as well as by race of borrower for home purchases (Appendix Figure D3). Finally, there is no effect of hospital closures on the average loan amounts either (Appendix Figure D4).

\section{Supplementary Analyses}

In this section, we probe more deeply into the effect of rural hospital closures on employmentinvestigating the existence of spillovers across space as well as the potential for differences in the magnitude of the effects based on characteristics of the closing hospital or its county of location.

\subsection{Border County Spillovers}

Our main empirical results do not reveal if the effects on health care employment from rural hospital market exits extend beyond the county experiencing the closure. Signing the direction of any such spillover effects a priori is also not possible. On the one hand, the negative labor market effects of a closure could be felt over a wider area than a single county if switching to a substitute hospital carries high costs for hospital-reliant (or dependent) health care firms in neighboring areas or if the relevant labor market is larger than a county. Alternatively, surrounding areas could 
experience a positive labor market shock if health care workers from the closure county migrate to surrounding areas as their next best employment opportunity.

To test for spillovers to the labor markets of nearby counties, we re-estimate our CSDID, Stacked DID, and TWFE models with a redefined treatment group. First, we exclude the counties which experience hospital closures from the analysis (i.e., the treatment counties in our main analyses). Then, we consider all counties sharing a border with the closure counties as the new treatment group and assign them the closure date of the true closure county with which they share a border. All other elements of the estimation underlying the results from Section 5 remain the same. $^{23}$

We find no evidence that the labor markets of neighboring counties are affected by the rural hospital closures. Figure 7 presents the results relying on the CSDID estimation, and Appendix Figures A4 and B4 show the Stacked DID and TWFE specifications, respectively. The CSDID event-time estimates for overall employment (panel (A)), private sector employment (panel (B)), health care employment (panel (C)) and non-health care employment (panel (D)) uniformly demonstrate very stable patterns before and after the rural hospital exit in the shared border county. Similarly, no clear evidence of spillovers to the labor market of neighboring counties are found when using alternative DID estimation methods (see Appendix Figures A4 and B4).

One interpretation of these findings is that when health care workers are induced to leave an area through the closure of the local hospital, they relocate to a completely different area of the

\footnotetext{
${ }^{23}$ We have also performed a second version which aggregates the quarter-year employment levels for all border counties together so that the subsequent DID estimation considers them as a single, aggregated treatment unit. For example, if a given true treatment county shares a border with five other counties, then the first estimation would let each of the five counties be a spillover treatment unit in the estimation; however, the second estimation would aggregate the employment totals from the five counties into a single, spillover treatment unit. This alternative approach to constructing the spillover treatment group units has no material impact on the estimates or conclusions from these analyses (results available by request).
} 
US. Unfortunately, our empirical strategy is not well suited to examining a more diffuse pattern of migration. Additionally, our data are only able to capture changes in employment on net. It remains a possibility that subtler changes in surrounding areas (i.e., border counties) take place following a rural hospital closure - e.g., a loss of certain health care jobs being offset by gains in other health care jobs when workers reallocate across geographies. We lack the data granularity to rule out such nuanced labor market adjustments post-closure.

\subsection{Hospital and County-Level Heterogeneity}

\subsubsection{Sources of Heterogeneity}

Our last set of empirical exercises investigate whether there is evidence of heterogeneity in the economic impacts of rural hospital closures. In what follows, we do so by simply stratifying our treatment group by a specific characteristic of interest and then re-estimating each of our three DID approaches. We then plot the resulting event-time estimates for each treatment (sub)group for visual comparison.

We begin by examining whether the effects of rural hospital closures on local economic outcomes differ by the degree of closure: full versus partial hospital closures. Partial closures (or facility repurposing efforts) commonly include transitions to emergency services, urgent care, outpatient care, and/or skilled nursing facilities, which could plausibly preserve many of the jobs previously attached to the inpatient care unit. However, the decision to preserve some service lines, rather than implement a full shutdown, likely reflects a variety of market conditions and possibly their evolution leading up to closure deliberations and decisions. Figure 8, for example, shows the 30 -year trends in median household income and prevailing poverty rate for three mutually exclusive county types: 1) those experiencing a partial closure 2) those experiencing a full closure 
and 3) those never experiencing either type of rural hospital closure and belonging to our DID control groups. Counties whose rural hospitals eventually fully close have consistently lower incomes and higher poverty rates on average, compared to the other two groups, which tend to look more similar. We thus view these supplementary analyses as largely descriptive. Yet, given the similarity between the partial closures we observe in the data and the goal of recent policy proposals, which have essentially advocated for subsidy programs that would favor partial closures over full closures of rural hospitals, and the fact that existing literature has typically not differentiated between true closures and rural hospital conversions (Kaufman et al. 2016), we believe these analyses are still informative.

The second source of heterogeneity that we examine focuses on the closing hospital type. As previously discussed (Section 2), the longstanding CAH program aims to forestall rural hospital closures in order to preserve access for surrounding communities. The program design and its possible targeting suggest that the effects of closing a CAH designated hospital could differ from other, non-CAH facilities. In our analytic data, $40 \%$ of the observed rural hospital closures belong to the CAH program.

The final potential source of heterogeneity that we examine is based on the importance of the health care sector in the local economy at baseline (i.e., before a rural hospital closure takes place). As a proxy for the relative importance of the sector, we calculate the share of private sector jobs classified as belonging to health care industries for each county in 2004 (one year prior to any rural hospital closures observed in our data) via the QCEW employment data. We then partition counties based on being at or above versus below the median health care jobs share in the resulting distribution from our analytic sample of counties. 


\subsubsection{Heterogeneity Results}

The CSDID figures estimating our main results separately accordingly to each source of heterogeneity (running our main empirical specification separately in each subgroup) are displayed in Figure 9. Appendix Figures A5 and B5 do the same for the Stacked DID and TWFE estimations, respectively. While we focus on the labor market outcomes (i.e., where we observe rural hospital closure effects in the results from Section 5), Appendix C contains analogous heterogeneity results for our consumer financial health and housing market outcomes. ${ }^{24}$

Figure 9A offers suggestive evidence that partial hospital closures have a smaller impact on the local labor market compared to full closures. The initial decline in health care jobs is not as steep when the rural hospital only partially shuts down, and the point estimates are approximately $50-60 \%$ as large as those belonging to the full closure counties. Taken at face value, areas which are able to repurpose an existing hospital into some other type of health care facility may benefit from a smaller overall shock to their local health care industries and economies. Such an approach, which some recent policy proposals would encourage, may also be easier to adapt to local health needs and priorities than the more rigid requirements that must be met to qualify for enhanced Medicare reimbursements under the $\mathrm{CAH}$ program. However, these findings are only descriptive, as it may also be the case that the labor markets of counties in which hospitals choose to partially close are stronger, and it is this underlying strength that drives both the decision to only partially close as well as the smaller decrease in aggregate health care employment. Neither closure type generates spillovers onto non-health care employment levels (Figure 9B).

\footnotetext{
${ }^{24}$ Corresponding figures for the consumer financial health and housing market outcomes in Appendix $\mathrm{C}$ show no consistent patterns of a heterogeneous impact along any of these margins. Thus, the findings in Appendix $\mathrm{C}$ do not indicate that our main analyses and results from Sections 4 and 5 are masking rural hospital closure effects.
} 
We find no evidence of differing effects of rural hospital closures on private sector employment either when stratifying by hospital type (CAH versus non-CAH; panels $\mathrm{C}$ and $\mathrm{D})$ or by baseline reliance on the health care sector (panels E and F in Figure 9). Thus, neither CAH closures nor a stronger labor market tilt toward health care drive the main effects of rural hospital closures on health care jobs reported in Section 5. The findings in Figure 9 further indicate that we are not masking underlying heterogeneity in the closure impact on non-health care jobs along any of these three dimensions within our main analyses.

\section{Conclusions}

The hospital industry captures the largest share of annual US health care spending among all medical service suppliers; yet, certain members of the industry - namely rural hospitals - have experienced a wave of financial insolvencies during the past decade. Rural hospitals' clinical contributions to health care delivery as well as their potential broader economic impacts in lower resourced and less populated communities are sometimes used to advocate for government intervention to stave off closures (MedPAC 2016; Wishner et al. 2016; Associated Press 2019, 2020a, 2020b; Frakt 2019); though, the evidence base for doing so is incomplete.

Empirically, we find weaker employment following rural hospital closures. However, the losses are entirely concentrated among health care-related jobs. In contrast, aggregate consumer financial health and local housing markets are not affected by the local hospital shutting downat least not over the short- to medium-run. ${ }^{25}$ The negative employment effects are sizable, however. The $10-12 \%$ reduction in health care jobs translates to a $2 \%$ decline in private sector employment in the county overall. Furthermore, the magnitude of the effect relative to the number

\footnotetext{
${ }^{25}$ We also do not find strong changes in county-level annual population levels, poverty rates, median household income, or net migration (Figure D5).
} 
of workers at the average rural hospital closing in our data implies that roughly half of these job losses take place at other health care firms in the county. While we do not observe job losses among non-health care industries, these findings are indicative of a substantive negative externality due to within-sector agglomeration economies tied to the presence of a local hospital.

Even in the absence of evidence for broader economic harms (e.g., greater consumer financial strain or depressed housing markets in the aggregate), the fact that rural hospital closures can directly and indirectly cause health care job losses is important and, in theory, could justify sustained (or increased) subsidies to rural hospitals to forestall market exits, especially if worker adjustment costs are large. However, there are several reasons why health care workers may face relatively fewer frictions when transitioning to new employment following a hospital closureinduced job loss than workers in other industries experiencing negative shocks to employmentsuch as those working in manufacturing (e.g., Artuç, Chaudhuri, and McLaren 2010; Autor et al. 2014; Balsvik, Jensen, and Salvanes 2015; Utar 2018; Traiberman 2019). First, outside options may be more plentiful for these displaced workers, all else equal. Health care job growth has outpaced the rest of the US economy for the past decade and is projected to continue to do so for the next decade (Stiegler, Martiniano, and Forte 2021). Health care employment is also known for being less sensitive to macroeconomic conditions, particularly downturns in the business cycle (Chen, Lo Sasso, and Richards 2018; Dillender et al. 2021). ${ }^{26}$ Second, in non-health care labor markets, negative shocks to employment can be unevenly felt across skill levels and occupations within an industry, with higher skilled workers often emerging relatively unscathed (Dix-Carneiro 2014; Balsvik, Jensen, and Salvanes 2015; Utar 2018; Traiberman 2019). Health care workers in

\footnotetext{
${ }^{26}$ Relatedly, Utar (2018) shows that a growing service sector, more broadly, softens the impact of a negative shock to manufacturing, specifically, especially among workers with higher education or more service-specific vocational education prior to the shock.
} 
these rural counties with jobs directly or indirectly tied to medical services are unlikely to experience the specific human capital destruction that drives up workers' adjustment costs-i.e., their knowledge and (high) skills are in stable, if not, growing demand across the US economy on the whole.

While many health care workers are relatively high skilled, around one third of the employees in the closing hospitals are in full-time, non-clinical roles, and presumably some of these workers fall into the relatively low-skill type and are perhaps at greater risk of experiencing larger adjustment costs. ${ }^{27}$ Yet, even this subgroup of lower skilled workers could fare better than lower skilled workers in other industries since many of their non-clinical skills (e.g., customer service experience, financial management tools, administrative support functions, etc.) are easily transferable to other sectors and service industries - and as noted above, may even have identical job opportunities elsewhere within the health care sector due to its robust job creation. This situation contrasts with lower skilled, lower earning workers in manufacturing where they may suffer prolonged unemployment spells, detach from the labor market completely, and/or churn through additional manufacturing jobs and thereby remain exposed to future (negative) employment shocks (Autor et al. 2014; Balsvik, Jensen, and Salvanes 2015). Thus, based on characteristics of the industry and the jobs themselves, displaced health care workers seem much less likely to be forced to forgo their accumulated human capital or to find themselves trapped in a cycle of job instability compared to other industries often studied in the literature.

\footnotetext{
${ }^{27}$ Authors' calculations using the AHA survey data to determine what percent of full-time workers, on average, are not physicians, dentists, medical trainees, or nurses of any type. Of note, some jobs may still be relatively clinical that do not fall into these categories identified by the survey (e.g., lab or surgical technicians). Other research finds that nearly $30 \%$ of entry level workers in health care transition to other occupations within ten years (Snyder, Dahal, and Frogner 2018) - suggesting substantive worker mobility across jobs and job types, even among those with less education and credentials.
} 
Though our analysis of the economic effects of rural hospital closures from 2005-2017 does not reveal economic damage as severe or far-reaching, on average, as sometimes feared or portrayed in media reporting and case studies, it does demonstrate a clear negative shock for local labor markets. It is not surprising, therefore, that local politicians and community leaders aim to forestall hospital closures or that the current federal administration has identified rural hospital closures as an issue of concern. ${ }^{28}$ When making policy decisions about how much to pay rural hospitals, Medicare's focus is on preserving health outcomes, rather than explicitly trying to save jobs for rural areas. However, the direction of contemporary policy momentum appears to be towards socially financing a narrower scope of in-person services in rural areas (e.g., emergent and outpatient care), which could impact both the access and economies of local communities. Our empirics offer suggestive evidence that the main economic harms from a hospital closure (health care job losses) might be partially mitigated, if there is not a full exit from the market. Our results are therefore timely, as the US hospital industry has been the recipient of large, new funding injections (via the CARES Act and follow-on legislation), with additional support possibly needed in the future. Allocating such funds wisely can ensure their efficient use and maximize their intended benefits.

\section{References}

AHA. 2018. "Trendwatch Chartbook 2018: Trends Affecting Hospitals and Health Systems." American Hospital Association, Washington DC, available online: https://www.aha.org/system/files/2018-07/2018-aha-chartbook.pdf.

Argys, Laura M., Andrew I. Friedson, M. Melinda Pitts, and D. Sebastian Tello-Trillo. 2020. "Losing Public Health Insurance: TennCare Reform and Personal Financial Distress." Journal of Public Economics, 187:

\footnotetext{
${ }^{28}$ For example, see here: https://www.whitehouse.gov/briefing-room/statements-releases/2021/07/09/fact-sheetexecutive-order-on-promoting-competition-in-the-american-economy/
} 
Artuç, Erhan, Shubham Chaudhuri, and John McLaren. 2010. "Trade Shocks and Labor Adjustment: A Structural Empirical Approach.” American Economic Review, 100 (6): 1008-1045.

Associated Press. 2019. "After Rural Hospital's Closure, County Seeks Other Options." September 23, 2019.

Associated Press. 2020. "Alabama Hospital to Close; $17^{\text {th }}$ to Shut Down in 10 Years." March 2, 2020.

Associated Press. 2020. "Bill to Assist Struggling Rural Hospitals Clears Kentucky House." February 28, 2020.

Autor, David H., David Dorn, Gordon H. Hanson, and Jae Song. 2014. "Trade Adjustment: Worker-Level Evidence.” Quarterly Journal of Economics, 129 (4): 1799-1860.

Bai, Ge, Farah Yehia, Wei Chen, and Gerard F. Anderson. 2020. "Varying Trends in the Financial Viability of US Rural Hospitals, 2011-17." Health Affairs 39 (6): 942-948.

Baicker, Katherine, and Amitabh Chandra. 2012. "The Health Care Jobs Fallacy." New England Journal of Medicine 366 (26): 2433-2435.

Balsvik, Ragnhild, Sissel Jensen, and Kjell G. Salvanes. 2015. "Made in China, Solid in Norway: Local Labor Market Effects of an Import Shock." Journal of Public Economics, 127: 137-144.

Bartik, Timothy J. 2020. "Using Place-Based Jobs Policies to Help Distressed Communities." Journal of Economic Perspectives, 34 (3): 99-127.

Brady, Michael. 2020. "HHS Awards More than \$160 Million to Rural Providers." Modern Healthcare, April 22 2020, Crains Communications Inc.

Buchmueller, Thomas C., Mireille Jacobson, and Cheryl Wold. 2006. "How Far to the Hospital? The Effect of Hospital Closures on Access to Care." Journal of Health Economics 25 (4): 740-761.

Callaway, Brantly, and Pedro H.C. Sant'Anna. 2021. "Difference-in-Differences with Multiple Time Periods.” Journal of Econometrics, 225 (2): 200-230.

Capps, Cory, David Dranove, and Richard C. Lindrooth. 2010. "Hospital Closure and Economic Efficiency." Journal of Health Economics, 29: 87-109.

Carrol, Caitlin. 2019. "Impeding Access of Promoting Efficiency? Effects of Rural Hospital Closure on the Cost and Quality of Care." Unpublished manuscript available from author. 
Cass, Andrew. 2022. "CMS' Proposed Rule for Rural Emergency Hospital Designations: 8 Things to Know.” Becker's Hospital Review. https://www.beckershospitalreview.com.

Chartis Center for Rural Health. 2020. "The Rural Health Safety Net Under Pressure: Rural Hospital Vulnerability.” February 2020, The Chartis Group.

Chen, Alice, Anthony Lo Sasso, and Michael R. Richards. 2018. "Graduating into a Downturn: Are Physicians Recession Proof?” Health Economics, 27 (1): 223-235.

Clemens, Jeffrey, and Stephen Miran. 2012. "Fiscal Policy Multipliers on Subnational Government Spending.” American Economic Journal: Economic Policy, 4 (2): 46-68.

Cross, Sarah H., Mandeep R. Mehra, Deepak L. Bhatt, Khurram Nasir, Christopher J. O’Donnell, Robert M. Califf, and Haider J. Warraich. 2020., "Rural-Urban Differences in Cardiovascular Mortality in the US, 1999-2017." Journal of the American Medical Association, 323 (18): 1852-1854.

Cross, Sarah H., Robert M. Califf, and Haider J. Warraich. 2021. "Rural-Urban Disparity in Mortality in the US from 1999-2019." Journal of the American Medical Association, 325 (22): 2312-2314.

Currie, Janet, Lucas Davis, Michael Greenstone, and Reed Walker. 2015. "Environmental Health Risks and Housing Values: Evidence from 1,600 Toxic Plant Openings and Closings." American Economic Review, 105 (2): 678-709.

Dillender, Marcus, Andrew Friedson, Cong Gian, and Kosali Simon. 2021. "Is Healthcare Employment Resilient and "Recession Proof"?" Inquiry, 58: https://doi.org/10.1177/00469580211060260.

Dix-Carneiro, Rafael. 2014. "Trade Liberalization and Labor Market Dynamics.” Econometrica, 82: 825-885.

Drew Germack, Hayley, Ryan Kandrack, and Grant R. Martsolf. 2019. "When Rural Hospitals Close, the Physician Workforce Goes.” Health Affairs 38 (12): 2086-2094.

Edmiston, Kelly D. 2019. "Rural Hospital Closures and Growth in Employment and Wages." KCFed Economic Bulletin, Federal Reserve Bank of Kansas Cit, July 16 2019, www.kansascityfed.org/economicbulletin.

Eliason, Paul J., Benjamin Heebsh, Ryan C. McDevitt, and James W. Roberts. 2019. "How Acquisitions Affect Firm Behavior and Performance: Evidence from the Dialysis Industry." Quarterly Journal of Economics: 221-267.

Ellison, Glenn, and Edward L. Glaeser. 1999. "The Geographic Concentration of Industry: Does Natural Advantage Explain Agglomeration?" American Economic Review: Papers \& Proceedings, 89 (5): 311-316. 
Fort, Teresa C., Justin R. Pierce, and Peter K. Schott. 2018. "New Perspectives on the Decline of US Manufacturing Employment.” Journal of Economic Perspectives, 32 (2): 47-72.

Fox, William F., and Matthew N. Murray. 2004. "Do Economic Effects Justify the Use of Fiscal Incentives?" Southern Economic Journal, 71 (1): 78-92.

Frakt, Austin B. 2019. “The Rural Hospital Problem.” Journal of the American Medical Association 321 (23): 2271-2272.

Frogner, Bianca K. 2018. "The Health Care Job Engine: Where Do They Come from and What Do They Say About Our Future?” Medical Care Research and Review, 75 (2): 219-231.

GAO. 2020. Rural Hospital Closures: Affected Residents Had Reduced Access to Health Care Services. Government Accountability Office (GAO) December 22, 2020. Washington DC. GAO-21-93.

Garthwaite, Craig, Tal Gross, and Matthew Notowidigdo. 2018. "Hospitals as Insurers of Last Resort." American Economic Journal: Applied Economics 10 (1): 1-39.

Glaeser, Edward, and Joshua D. Gottlieb. 2009. "The Wealth of Cities: Agglomeration Economies and Spatial Equilibrium in the United States." Journal of Economic Literature, 47 (4): 983-1028.

Greenstone, Michael, Richard Hornbeck, and Enrico Moretti. 2010. "Identifying Agglomeration Spillovers: Evidence from Winners and Losers of Large Plant Openings.” Journal of Political Economy, 118 (3): 536-598.

Goodman-Bacon, Andrew. 2021. "Difference-in-Differences with Variation in Treatment Timing." Journal of Econometrics, 225 (2): 254-277.

Gowrisankaran, Gautam, Claudio Lucarelli, Phillip Schmidt-Dengler, and Robert Town. 2018. "Can Amputation Save the Hospital? The Impact of the Medicare Rural Flexibility Program on Demand and Welfare.” Journal of Health Economics, 58: 110-122.

Gurjal, Kritee, and Anirban Basu. 2019. "Impact of Rural and Urban Hospital Closures on Inpatient Mortality." NBER Working Paper Series, No. 26182.

Hart, L. Gary, Michael J. Pirani, and Roger A. Rosenblatt. 1995. "Most Rural Towns Lost Physicians after Their Hospitals Closed." Rural Development Perspectives 10 (1): 17-21.

Holmes, George M., Rebecca T. Slifkin, Randy K. Randolph, and Stephanie Poley. 2006. "The Effect of Rural Hospital Closures on Community Economic Health." Health Services Research 41 (2): 467-485. 
Iglehart, John K. 2018. “The Challenging Quest to Improve Rural Health Care.” New England Journal of Medicine, 378 (5): 473-479.

Joynt, Karen E., Paula Chatterjee, E. John Orav, and Ashish K. Jha. 2015. "Hospital Closures Had No Measurable Impact on Local Hospitalization Rates or Mortality Rates, 2003-11.” Health Affairs 34 (5): 765-772.

Kacik, Alex. 2020. "A Quarter of Rural Hospitals Are at Risk of Closing.” Modern Healthcare, April 8, 2020, Crain Communications Inc.

Kacik, Alex. 2022. "New Rural Hospital Model Could Preserve Communities, Jobs.” Modern Healthcare, March 24, 2022, Crain Communications Inc.

Kaufman, Brystana G., Sharita R. Thomas, Randy K. Randolph, Julie R. Perry, Kristie W. Thompson, George M. Holmes, and George H. Pink. 2016. "The Rising Rate of Rural Hospital Closures." Journal of Rural Health 32: 35-43.

Lindrooth, Richard C., Anthony T. LoSasso, and Gloria J. Bazzoli. 2003. "The Effect of Urban Hospital Closure on Markets.” Journal of Health Economics, 22 (5): 691-712.

Lindrooth, Richard C., Marcelo C. Perraillon, Rose Y. Hardy, and Gregory J. Tung. 2018. "Understanding the Relationship between Medicaid Expansions and Hospital Closures." Health Affairs, 37 (1): 111-120.

McCarthy, Sean, Dylana Moore, W. Andrew Smedley, Brandon M. Crowley, et al. 2021. "Impact of Rural Hospital Closures on Health-Care Access." Journal of Surgical Research, 258: 170-178.

McNamara, Paul E. 1999. "Welfare Effects of Rural Hospital Closures: A Nested Logit Analysis of the Demand for Rural Hospital Services.” American Journal of Agricultural Economics, 81 (3): 686-691.

MedPAC. 2012. "Serving Rural Medicare Beneficiaries." Report to Congress: Medicare and the Health Care Delivery System, June 2012. Washington DC.

MedPAC. 2016. "Improving Efficiency and Preserving Access to Emergency Care in Rural Areas." Report to Congress: Medicare and the Health Care Delivery System, June 2016. Washington DC.

Miller, Katherine E. M., Hailey J. James, George Mark Holmes, and Courtney H. Van Houtven. 2020. "The Effect of Rural Hospital Closures on Emergency Medical Service Response and Transport Times." Health Services Research 55: 288-300.

Moretti, Enrico. 2004. "Workers Education, Spillovers and Productivity: Evidence from PlantLevel Production Functions.” American Economic Review, 94 (6): 656-690. 
Moretti, Enrico. 2010. "Local Multipliers." American Economic Review: Papers \& Proceedings, 100 (2): 373-377.

Nikpay, Sayeh, Craig Tschautscher, Nathaniel L. Scott, and Michael Puskarich. 2021.

"Association of Hospital Closures with Changes in Medicare-Covered Ambulance Trips among Rural Emergency Medical Services Agencies.” Academic Emergency Medicine, online ahead of print, https://doi.org/10.1111/acem.14273.

Ona, Lucia Y., Agus Hudoyo, and David Freshwater. 2007. "Economic Impact of Hospital Closure on Rural Communities in Three Southern States: A Quasi-Experimental Approach.” Journal of Regional Analysis \& Policy 37 (2): 155-164.

Pearson, David R., and Hassan Tajalli. 2003. "The Impact of Rural Hospital Closure on the Economic Health of the Local Communities." Texas Journal of Rural Health 21 (3): 4651.

Prager, Elena, and Matt Schmitt. 2021. "Employer Consolidation and Wages: Evidence from Hospitals." American Economic Review, 111(2): 397-427.

Probst, Janice C., Michael E. Samuels, James R. Hussey, David E. Berry, and Thomas C. Ricketts. 1999. "Economic Impact of Hospital Closure on Small Rural Counties, 1984 to 1988: Demonstration of a Comparative Analysis Approach." Journal of Rural Health 15 (4): 375-390.

Ramey, Valerie A. 2011. "Can Government Purchases Stimulate the Economy?" Journal of Economic Literature, 49 (3): 673-685.

Rosenbach, Margo L., and Debra A. Dayhoff. 1995. "Access to Care in Rural America: Impact of Hospital Closures." Health Care Finance Review 17 (1): 15-37.

Ross Johnson, Steven. 2018. "In Depth: Hospitals Tackling Social Determinants Are Setting the Course for the Industry." Modern Healthcare, August 25, 2018, Crains Communications Inc. Available online here: https://www.modernhealthcare.com/article/20180825/NEWS/180809949/in-depthhospitals-tackling-social-determinants-are-setting-the-course-for-the-industry.

Roth, Jonathan, Pedro H. C. Sant'Anna, Alyssa Bilinski, and John Poe. 2022. "What's Trending in Difference-in-Differences? A Synthesis of the Recent Econometrics Literature".

Sharfstein, Joshua M. 2016. “Global Budgets for Rural Hospitals.” Milbank Quarterly 94 (2): 255-259.

Slattery, Cailin, and Own Zidar. 2020. "Evaluating State and Local Business Incentives." Journal of Economic Perspectives, 34 (2): 90-118. 
Snyder, Cyndy R., Arati Dahal, and Bianca K. Frogner. 2018. "Occupational Mobility among Individuals in Entry-Level Healthcare Jobs in the USA." Journal of Advanced Nursing, 74 (7): 1628-1638.

Song, Lina D., and Soroush Saghafian. 2019. "Do Hospital Closures Improve the Efficiency and Quality of Other Hospitals?” SSRN 3318609, available here: https://pdfs.semanticscholar.org/e128/da2b61465dae871ed0228a9e5d252ac563d9.pdf.

Stiegler, Kristen, Robert Martiniano, and Gaetano Forte. 2021. Health Care Employment Projections, 2019-2029: An Analysis of Bureau of Labor Statistics Projections by Setting and by Occupation. Rensselaer, NY: Center for Health Workforce Studies, School of Public Health, SUNY Albany; August 2021.

Traiberman, Sharon. 2019. "Occupations and Import Competition: Evidence from Denmark." American Economic Review, 109 (12): 4260-4301.

Utar, Hale. 2018. "Workers Beneath the Floodgates: Low-Wage Import Competition and Workers' Adjustment." Review of Economics and Statistics, 100 (4): 631-647.

Vogler, Jacob. 2021. "Rural Hospital Closures and Local Economic Decline." SSRN Working Paper Series. Posted 9 March 2021. Available here: https://ssrn.com/abstract $=3750200$.

Wilson, Daniel J. 2012. "Fiscal Spending Jobs Multipliers: Evidence from the 2009 American Recovery and Reinvestment Act." American Economic Journal: Economic Policy, 4 (3): 251-282.

Wishner, Jane, Patricia Solleveld, Robin Rudowitz, Julia Paradise, and Larisa Antonisse. 2016. "A Look at Rural Hospital Closures and Implications for Access to Care: Three Case Studies." Issue Brief, Kaiser Commission on Medicaid and the Uninsured, Kaiser Family Foundation (KFF), July 2016 


\section{Figures}

Figure 1: Rural hospital closure taxonomy, 2005-2019

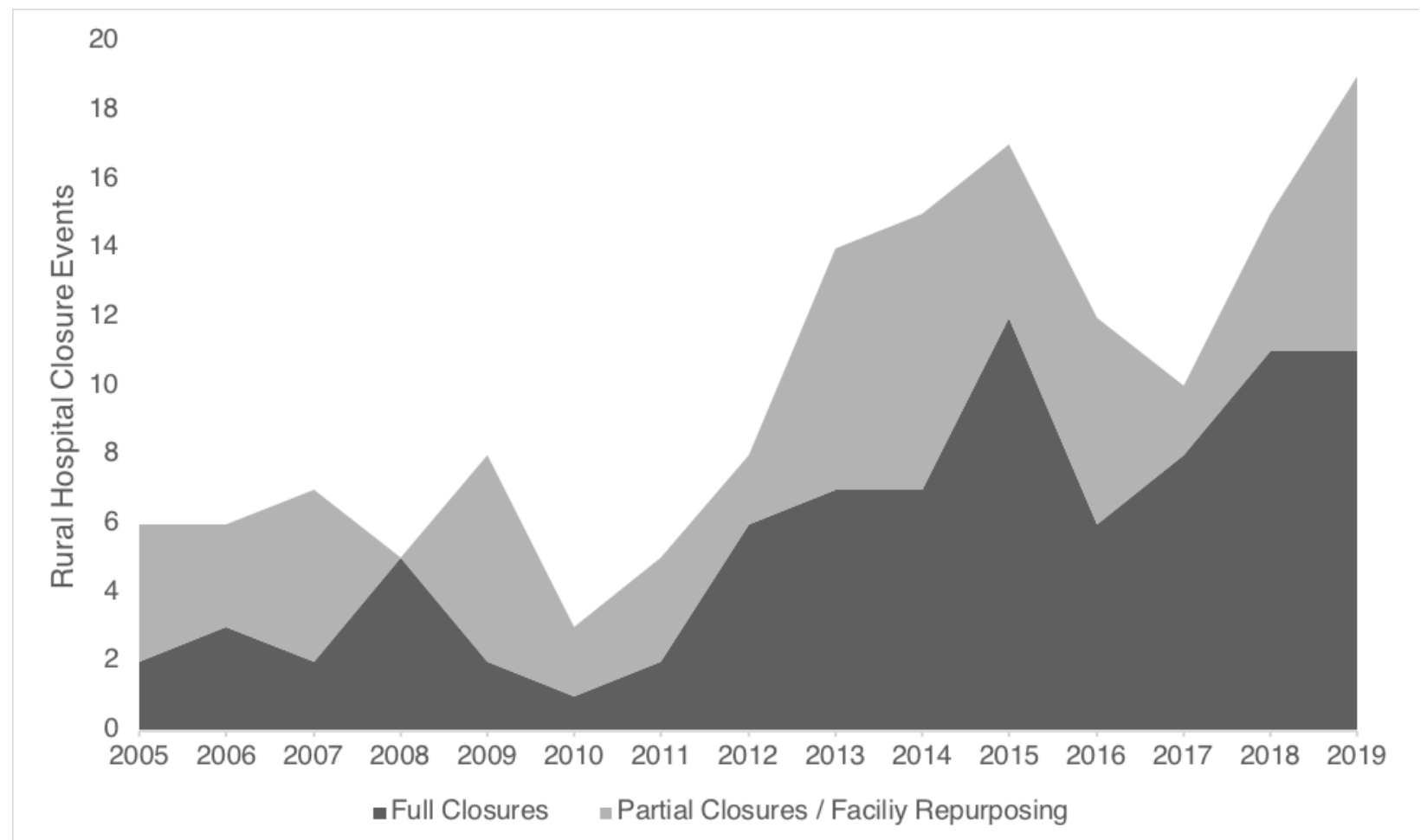

Notes: data from the University of North Carolina Cecil G. Sheps Center for Health Services Research. 
Figure 2: Geographic variation in rural hospital closure intensity, 2005-2019

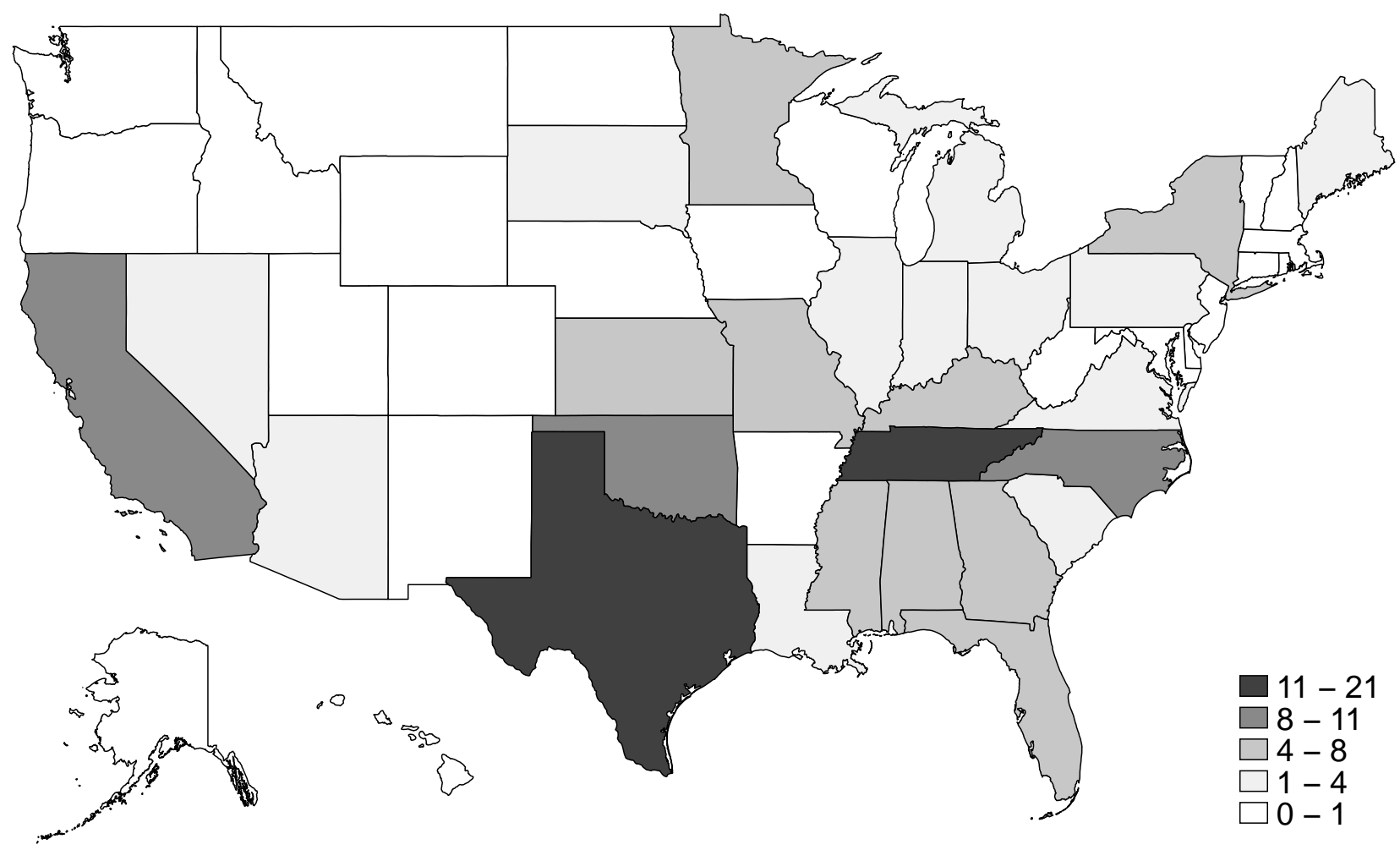

Notes: data from the University of North Carolina Cecil G. Sheps Center for Health Services Research and include full hospital closures as well as partial hospital closures. 
Figure 3: Rural closure effects on county-level employment: by estimation method

(A) Health care industry: cs-did

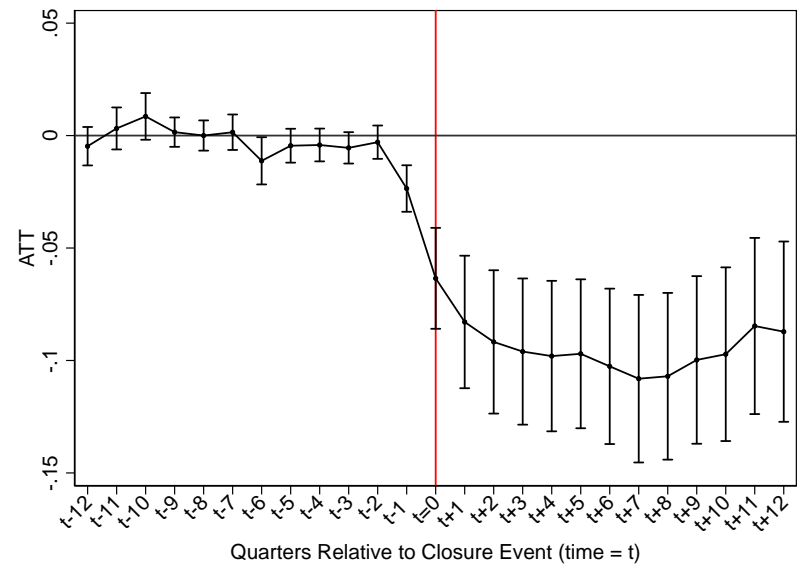

(C) Health care industry: stacked

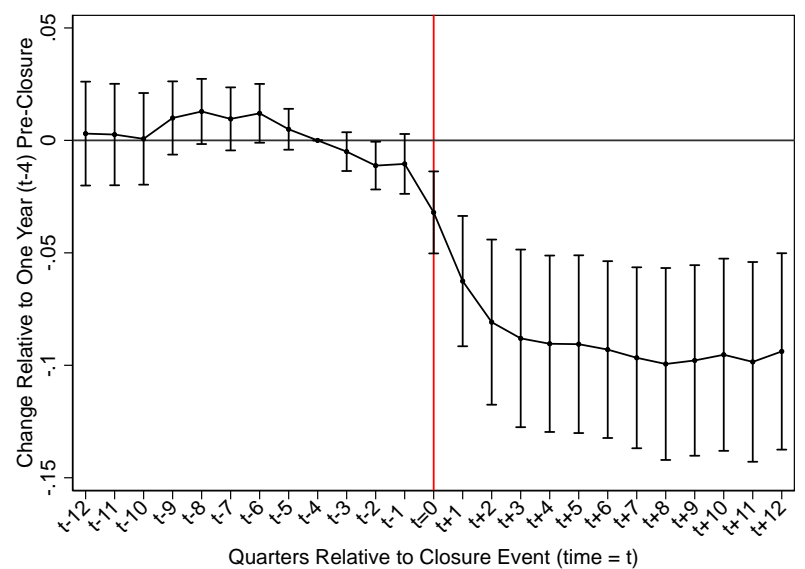

(E) Health care industry: twfe

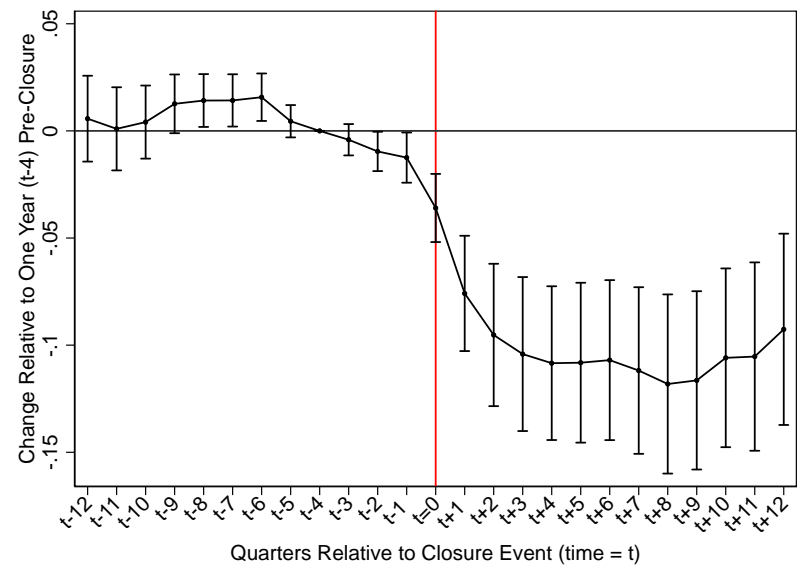

(B) Non-health care: cs-did

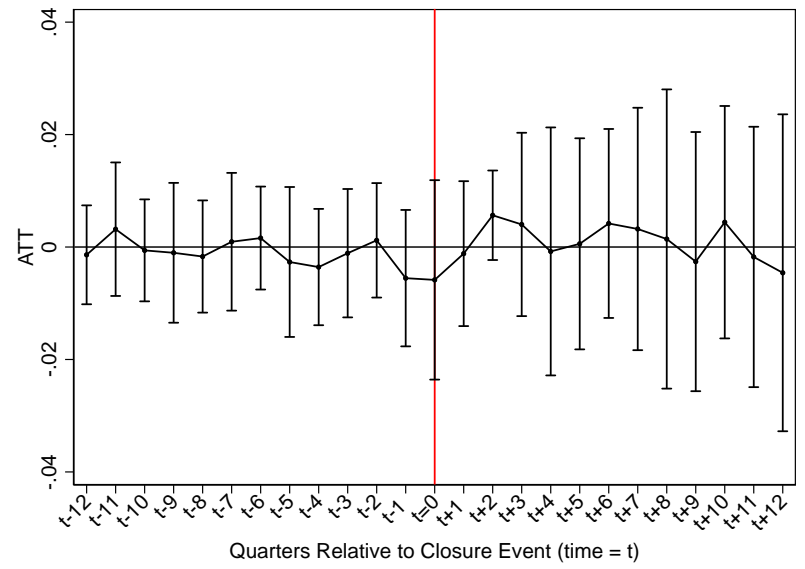

(D) Non-health care: stacked

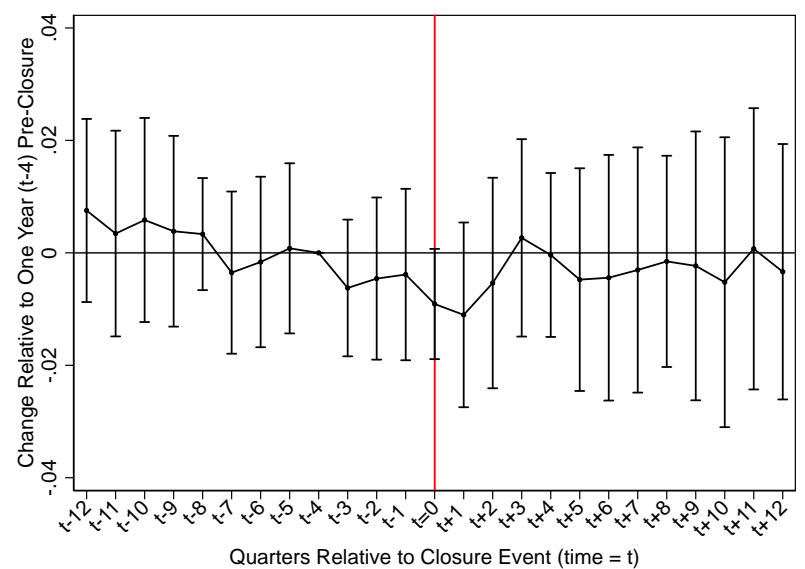

(F) Non-health care industry: twfe

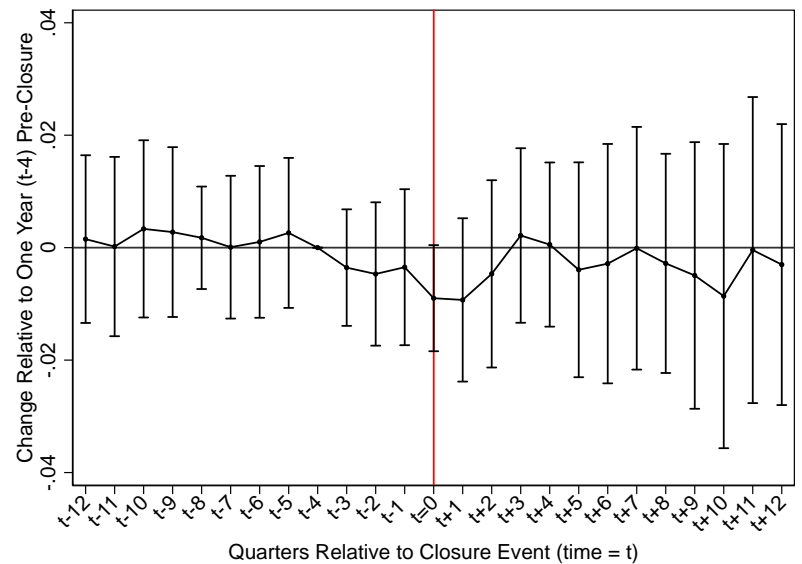

Notes: Employment data from the BLS QCEW, at the county-quarter level. Control group (never closure) counties are those that never experienced a rural hospital closure, had 25 percent or more of the county population living in a rural area according to the 2000 Census, and had a hospital present in the county as of 2005. Analytic data restricted to a balanced panel of counties with valid data across all variables for all time periods (2001Q1-2018Q4). County and year or year-quarter fixed effects included in two way fixed effect and stacked models, and standard errors clustered at the county level. Callaway and Sant'Anna (2021) estimator for DID models with panel data implemented using csdid in Stata. Event time point estimates and 95\% confidence intervals plotted. ATT stands for average treatment effect on the treated. 
Figure 4: Rural closure effects on county-level employment

(A) All jobs

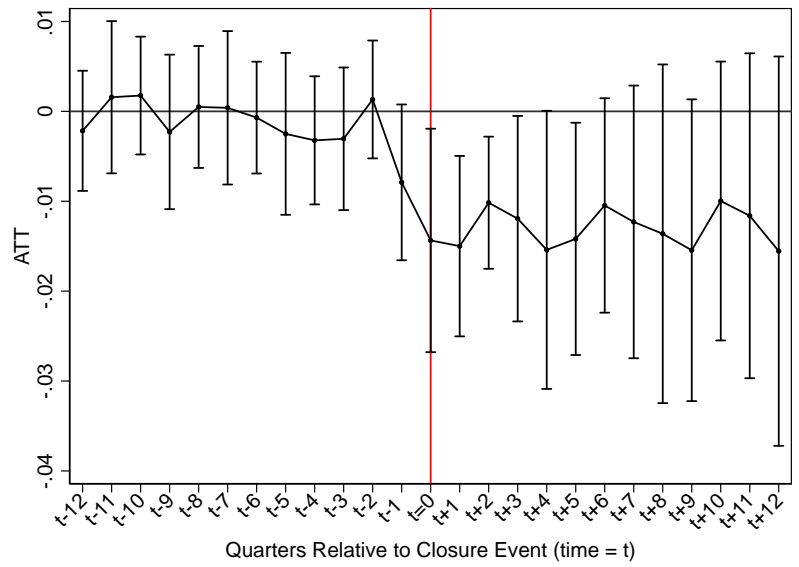

(C) Health care industry

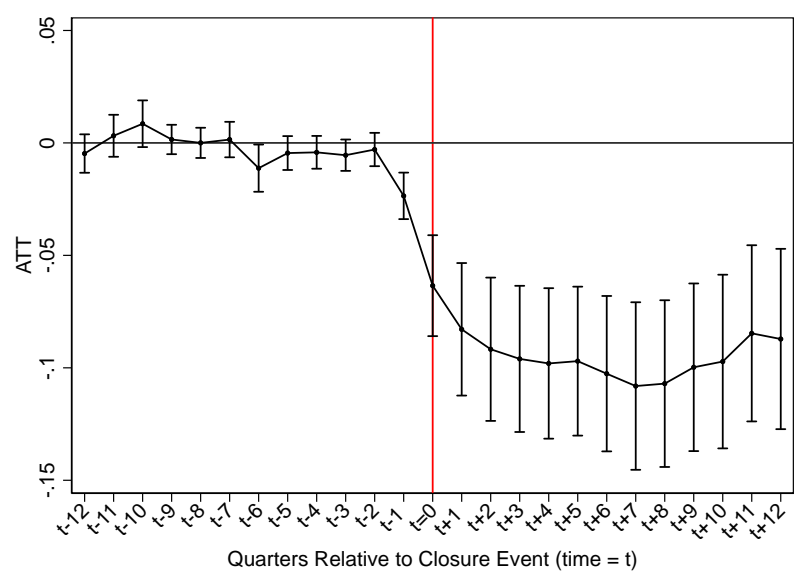

(B) Private sector

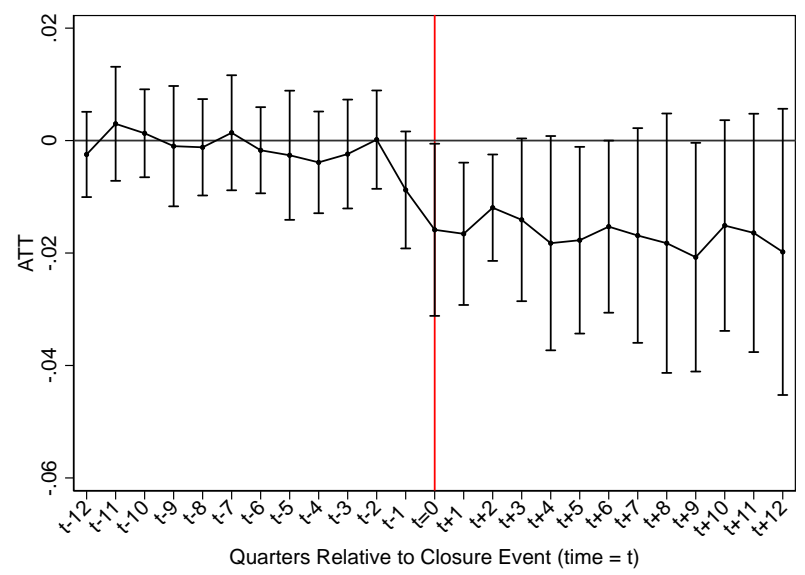

(D) Non-health care industry

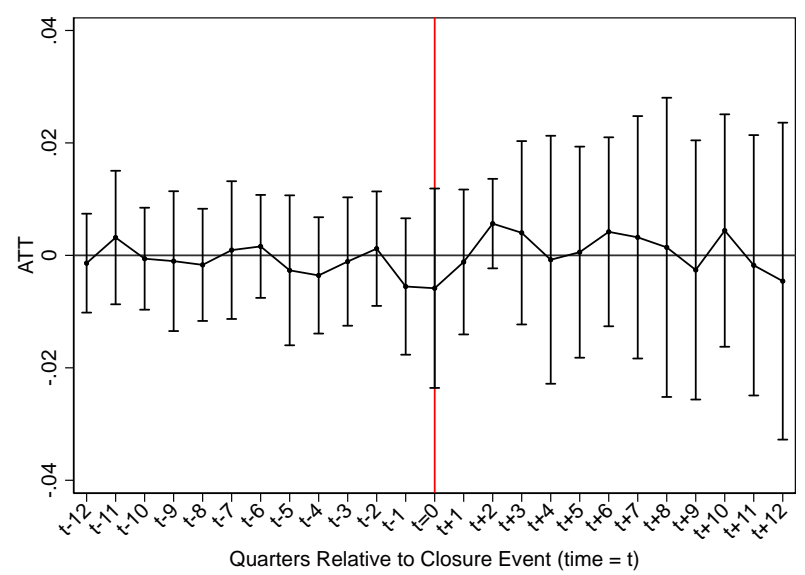

Notes: Employment data from the BLS QCEW, at the county-quarter level. Control group (never closure) counties are those that never experienced a rural hospital closure, had 25 percent or more of the county population living in a rural area according to the 2000 Census, and had a hospital present in the county as of 2005 . Analytic data restricted to a balanced panel of counties with valid data across all variables for all time periods (2001Q1-2018Q4). Callaway and Sant'Anna (2021) estimator for DID models with panel data implemented using csdid in Stata. Point estimates and 95\% confidence intervals plotted. ATT stands for average treatment effect on the treated. 
Figure 5: Rural hospital closure effects on consumer finances

(A) Risk score

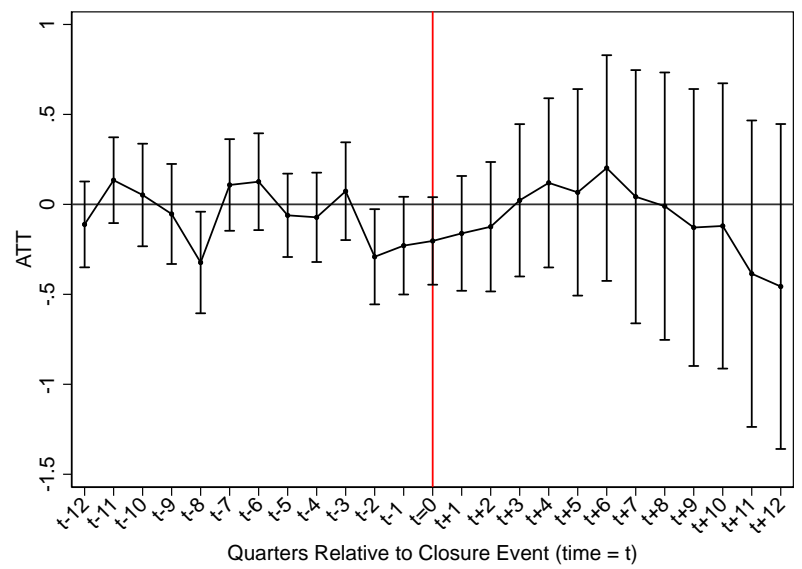

(C) Total balance past due

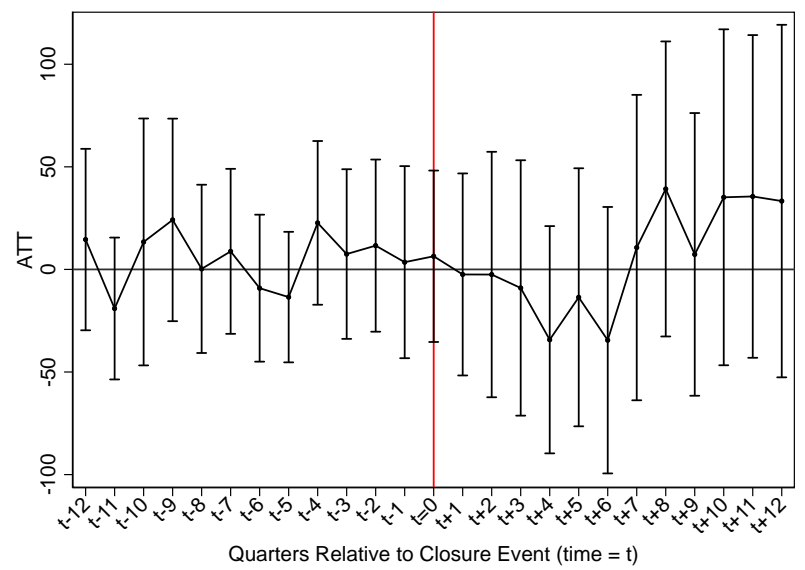

(B) Bankruptcies past 24-months

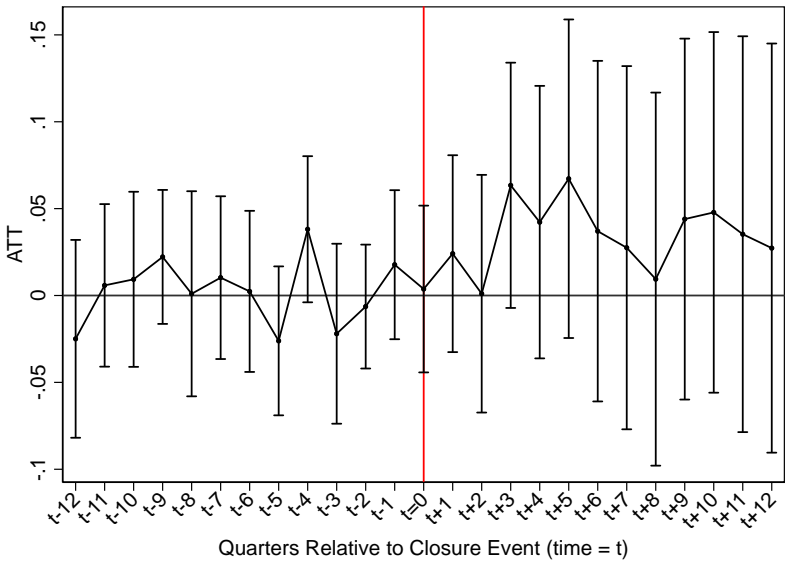

(D) Number of collections past 12-months

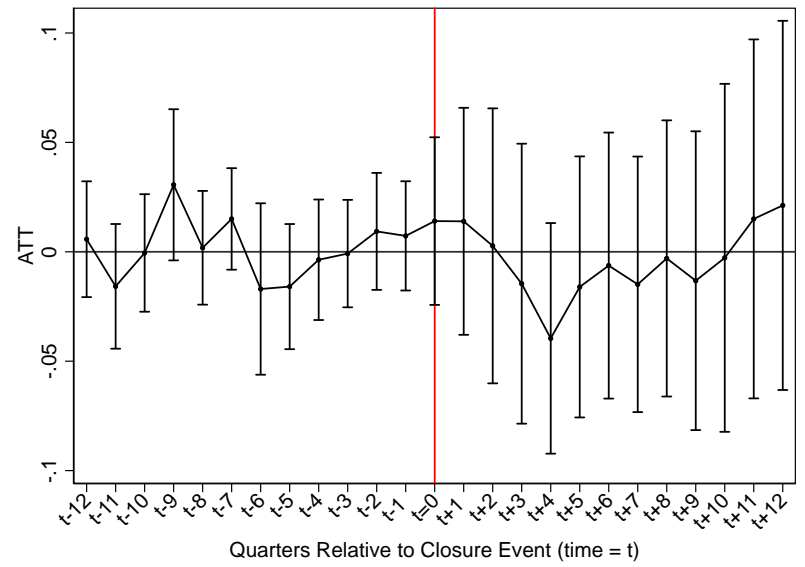

Notes: Data on consumer financial information comes from the Consumer Credit Panel, at the county-quarter level. Control group (never closure) counties are those that never experienced a rural hospital closure, had 25 percent or more of the county population living in a rural area according to the 2000 Census, and had a hospital present in the county as of 2005. Analytic data restricted to a balanced panel of counties with valid data across all variables for all time periods (2001Q1-2018Q4). Callaway and Sant'Anna (2021) estimator for DID models with panel data implemented using csdid in Stata. Event time point estimates and 95\% confidence intervals plotted. ATT stands for average treatment effect on the treated. 
Figure 6: Rural hospital closure effects on housing markets: number of loans

(A) Number of loans originated

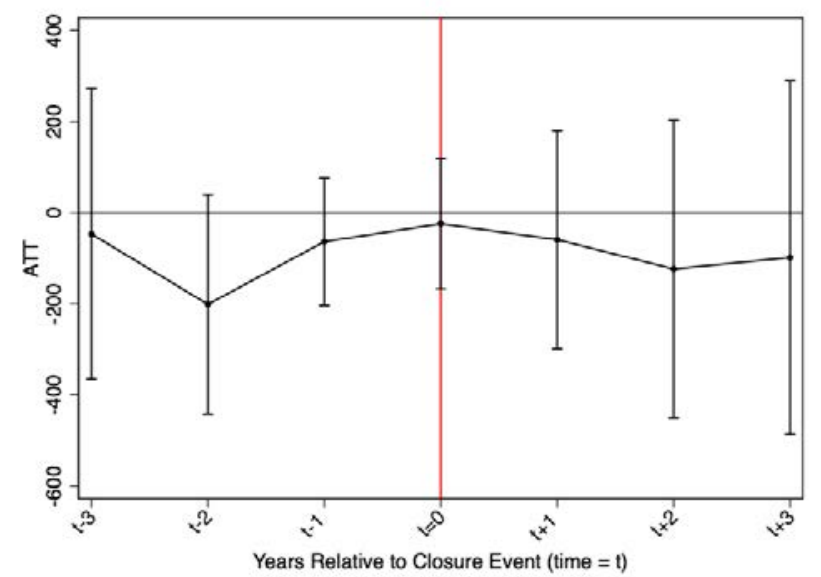

(B) Number of loans denied

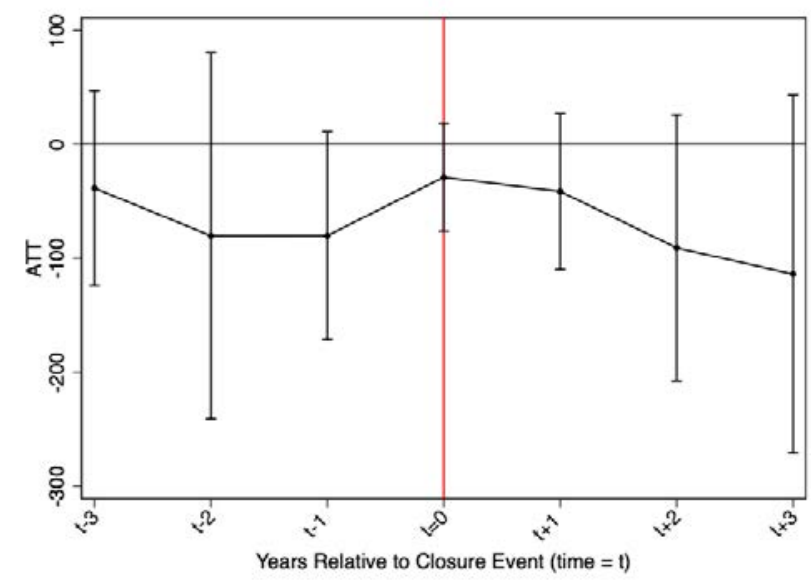

(C) Number of loans purchased

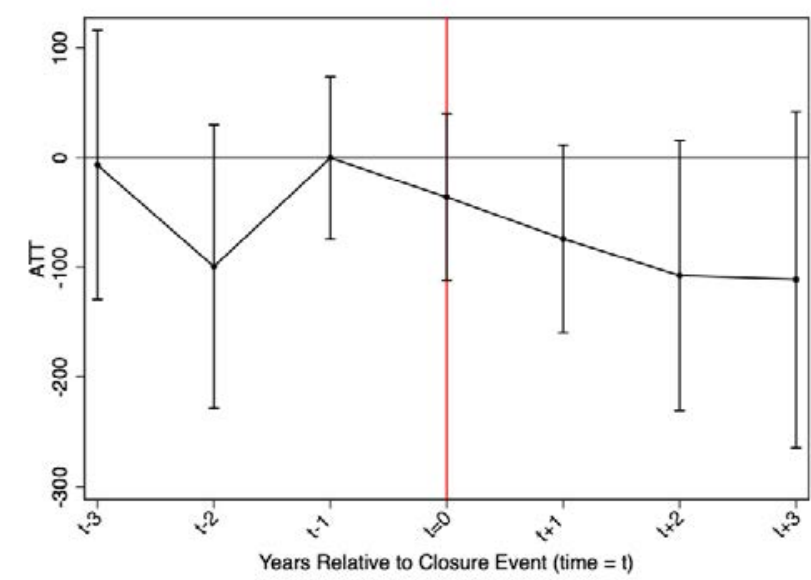

Notes: Data on loans from HMDA, at the county-year level. Control group (never closure) counties are those that never experienced a rural hospital closure, had 25 percent or more of the county population living in a rural area according to the 2000 Census, and had a hospital present in the county as of 2005. Analytic data restricted to a balanced panel of counties with valid data across all variables for all time periods (2001-2018). Callaway and Sant'Anna (2021) estimator for DID models with panel data implemented using csdid in Stata. Event time point estimates and 95\% confidence intervals plotted. ATT stands for average treatment effect on the treated. 
Figure 7: Rural closure effects on county-level employment: border county analysis

(A) All jobs

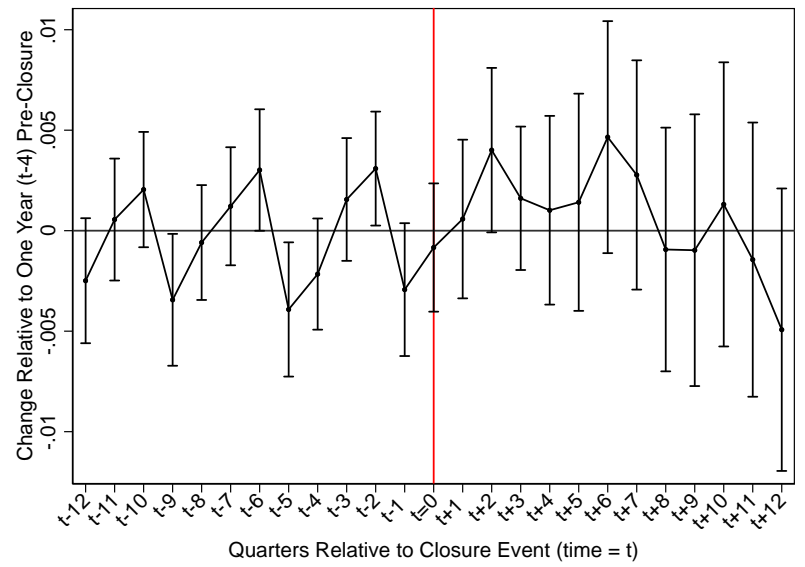

(C) Health care industry

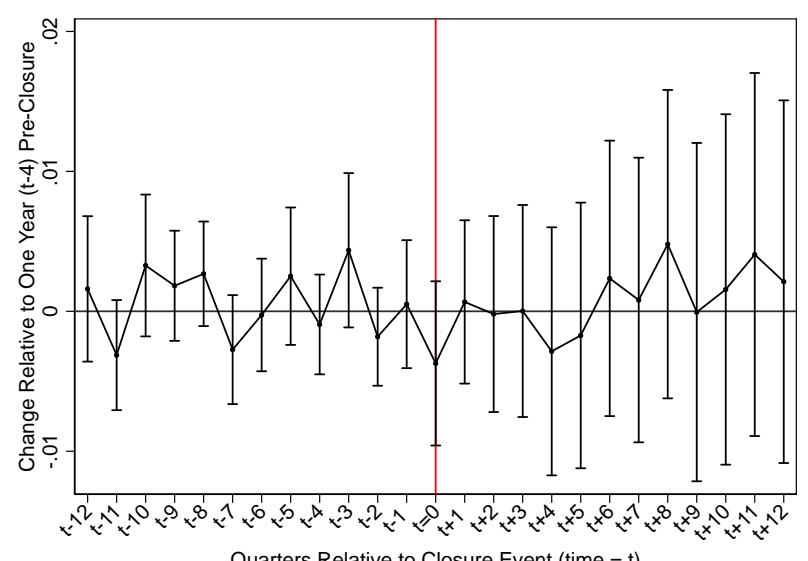

Quarters Relative to Closure Event (time $=\mathrm{t}$ )
(B) Private sector

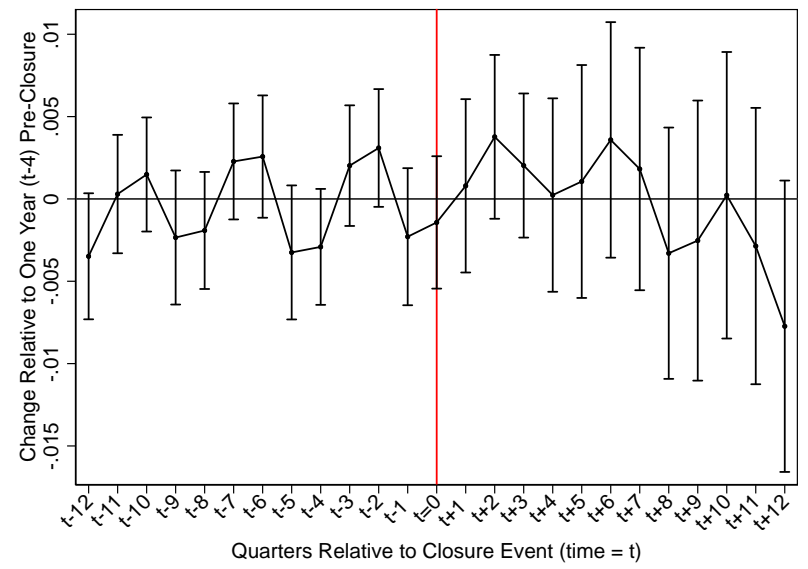

(D) Non-health care industry

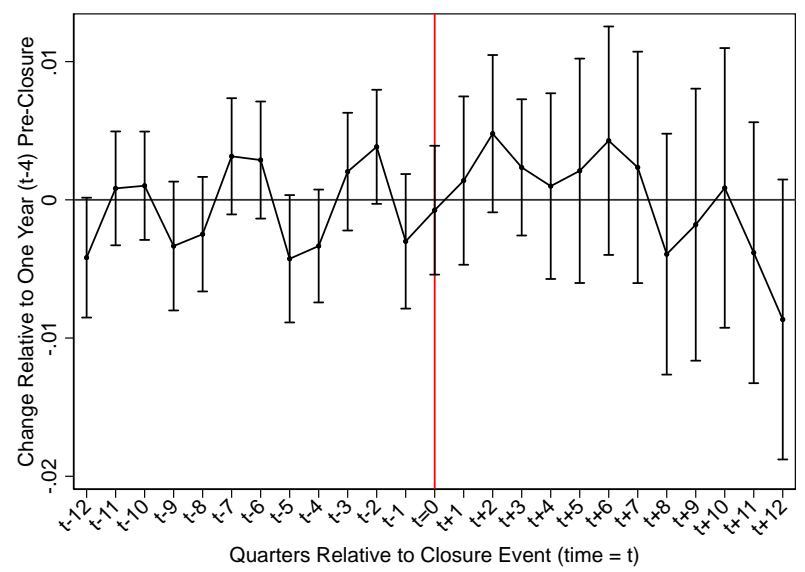

Notes: Analysis conducted using counties sharing a border with counties that experience a closure as the treated counties. Employment data from the BLS QCEW, at the county-quarter level. Control group (never closure) counties are those that never experienced a rural hospital closure, had 25 percent or more of the county population living in a rural area according to the 2000 Census, and had a hospital present in the county as of 2005. Analytic data restricted to a balanced panel of counties with valid data across all variables for all time periods (2001Q1-2018Q4). Callaway and Sant'Anna (2021) estimator for DID models with panel data implemented using csdid in Stata. Event time point estimates and 95\% confidence intervals plotted. ATT stands for average treatment effect on the treated. 
Figure 8: County characteristics by type of closure
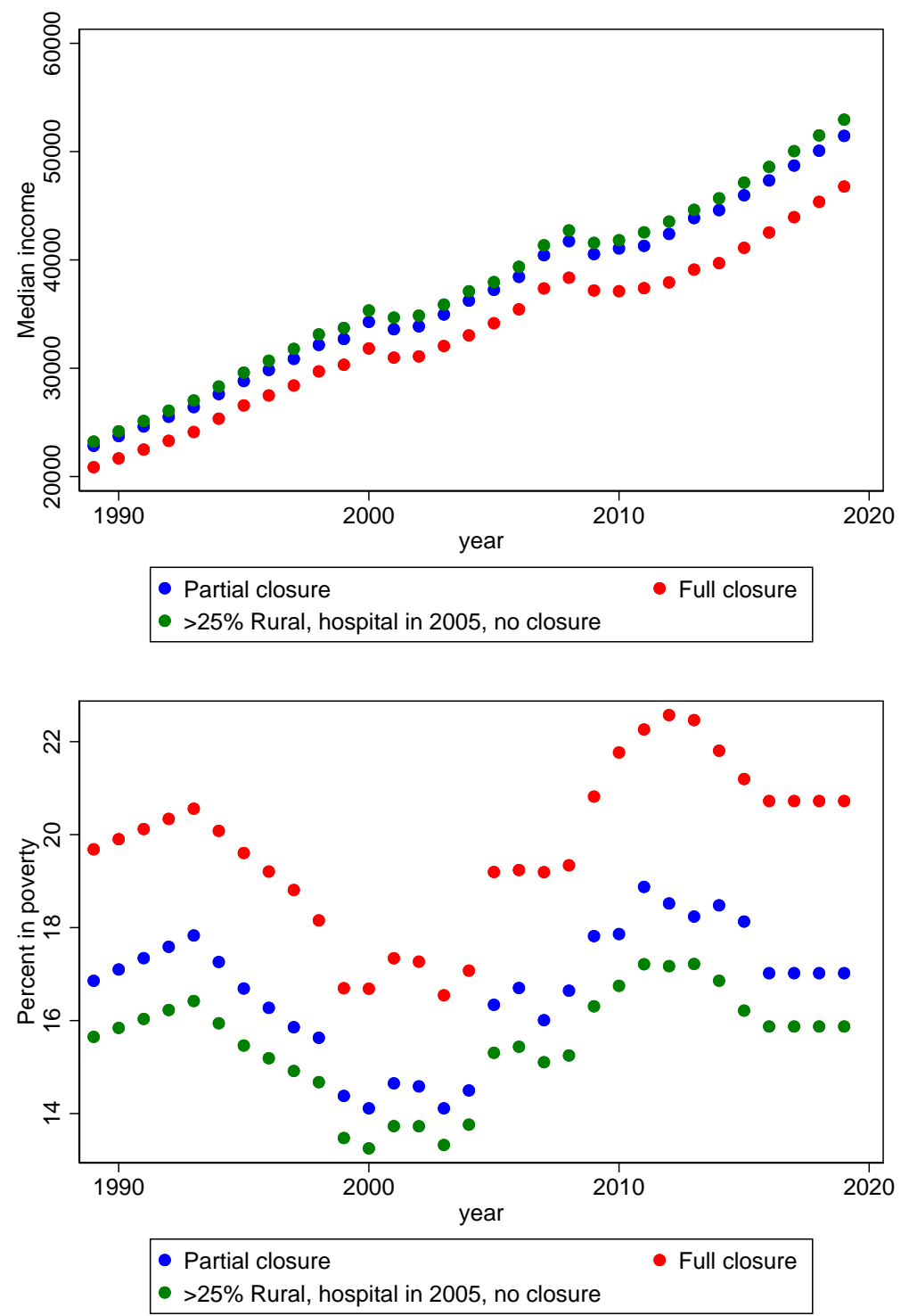

Notes: data on county-level median income and percent in poverty from the the Census Bureau's Small Area Income and Poverty Estimates. Counties in our sample are classified into three categories: those that ever experienced a partial closure, those that ever experience a full closure, and those that are at least $25 \%$ rural, but have never experienced a hospital closure. 
Figure 9: Rural closure effects on county-level employment: heterogeneity analysis

By type of closure: full or partial

(A) Health care industry

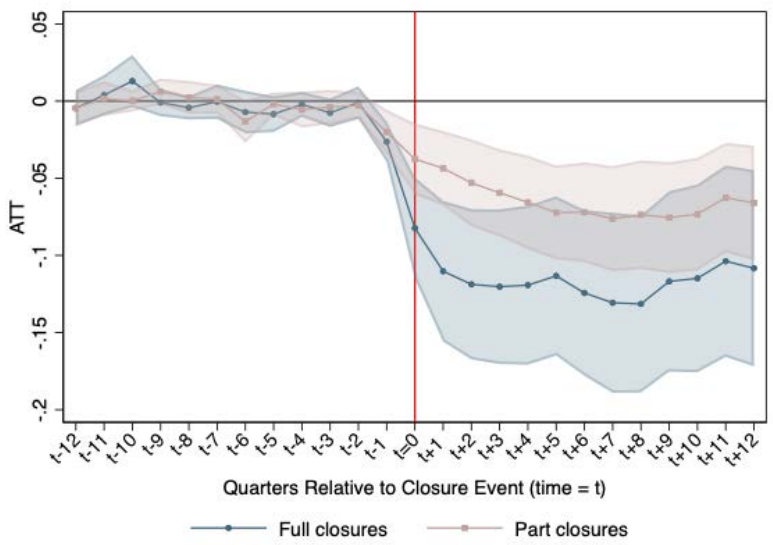

(B) Non-health care industry

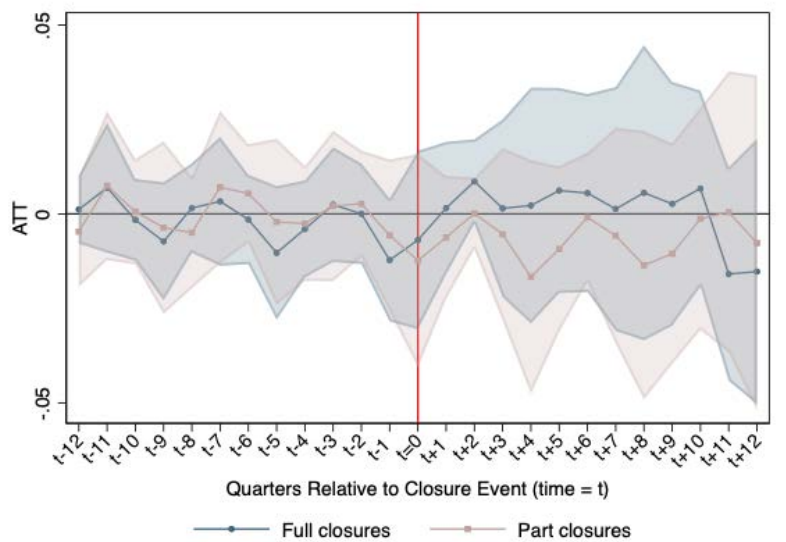

By type of closure: Critical Access Hospital

(C) Health care industry

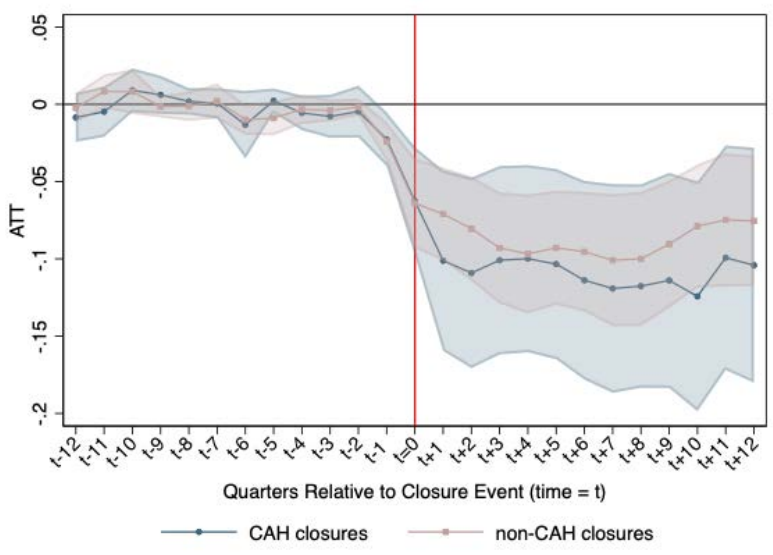

(D) Non-health care industry

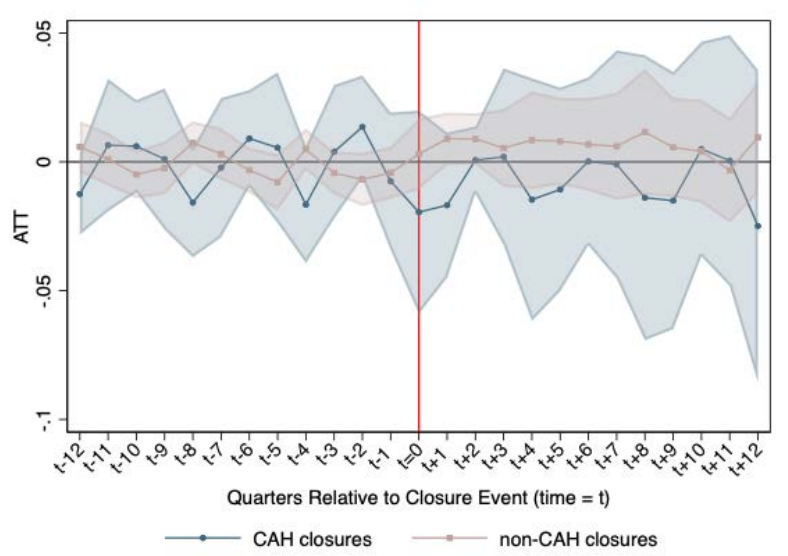

By county-level share employed in health jobs (2004)

(E) Health care industry

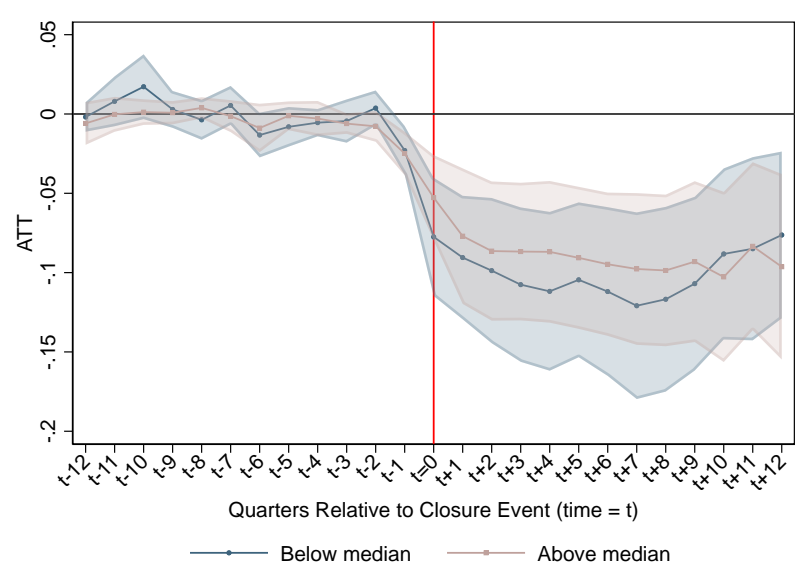

(F) Non-health care industry

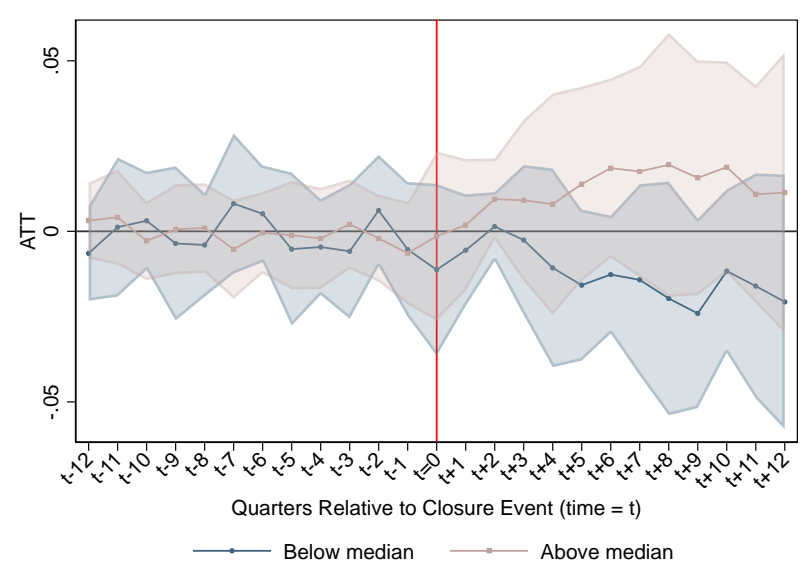

Notes: Employment data from the BLS QCEW, at the county-quarter level. Control group (never closure) counties are those that never experienced a rural hospital closure, had 25 percent or more of the county population living in a rural area according to the 2000 Census, and had a hospital present in the county as of 2005. Analytic data restricted to a balanced panel of counties with valid data across all variables for all time periods (2001Q1-2018Q4). Callaway and Sant'Anna (2021) estimator for DID models with panel data implemented using csdid in Stata. Event time point estimates and 95\% confidence intervals plotted. ATT stands for average treatment effect on the treated. 


\section{Tables}

Table 1: Summary statistics

\begin{tabular}{lcc}
\hline & Ever closure & Never closure \\
& & \\
\hline Total employment (median) & & \\
All & 33,840 & 29,794 \\
Private sector & 26,934 & 23,350 \\
Health care & 3,868 & 3,458 \\
Non-health care & 22,990 & 19,597 \\
\hline Unique counties & 117 & 1,642 \\
Observations & 8,424 & 118,224 \\
\hline \hline & Ever closure & Never closure \\
& & \\
\hline Consumer financial health & & \\
Risk score & 678 & 691 \\
Total balance past due & 1,024 & 849 \\
\# bills sent to collection (12m) & 0.914 & 0.794 \\
Bankruptcy (24m) x100 & 1.513 & 1.468 \\
\hline Unique counties & 128 & 1,869 \\
Observations & 9,216 & 134,549 \\
\hline \hline
\end{tabular}

Notes: Employment data from the Bureau of Labor Statistics' Quarterly Census of Employment and Wages (QCEW), at the county-quarter level. Data on loans from the Home Mortgage Disclosure Act (HMDA) Database, at the county-year level. Data on consumer financial information comes from the Federal Reserve Bank of New York Consumer Credit Panel (CCP), at the county-quarter level. Control group (never closure) counties are those that never experienced a rural hospital closure, had 25 percent or more of the county population living in a rural area according to the 2000 Census, and had a hospital present in the county as of 2005 . 